\title{
Current problems and future avenues in proteoliposome research
}

Andrea Marco Amati, Simone Graf, Sabina Deutschmann, Nicolas Dolder and Christoph von Ballmoos*

Department of Chemistry and Biochemistry, University of Bern, Freiestrasse 3, 3012 Bern, Switzerland

*Correspondence to christoph.vonballmoos@dcb.unibe.ch

\section{Abstract}

Membrane proteins are the gatekeepers between different biological compartments separated by lipid bilayers. Being receptors, channels, transporters, or primary pumps, they fulfill a wide variety of cellular functions and their importance is reflected in the increasing number of drugs that target membrane proteins. Functional studies of membrane proteins within a native cellular context, however, is difficult due to the innate complexity of the densely packed membranes. Over the past decades, detergentbased extraction and purification of membrane proteins and their reconstitution into lipid mimetic systems has been a very powerful tool to simplify the experimental system. In this review, we focus on proteoliposomes that have become an indispensable experimental system for enzymes with a vectorial function, including many of the here described energy transducing membrane proteins. We first address long standing questions on the difficulty of successful reconstitution and controlled orientation of membrane protein into liposomes. A special emphasis is given on coreconstitution of several membrane proteins into the same bilayer. Second, we discuss recent progress in the development of fluorescent dyes that offer sensitive detection with high temporal resolution. Finally, we briefly cover the use of giant unilamellar vesicles for the investigation of complex enzymatic cascades, a very promising experimental tool considering our increasing knowledge of the interplay of different cellular components.

All authors contributed to the writing and editing of the manuscript. 


\section{Introduction}

Lipid membranes are found in all living cells and provide several vital functions. Not only do they protect the organism from a potentially hostile environment, but they also allow chemical compartmentalization, e.g. reducing und oxidizing conditions in bacterial cytoplasm and periplasm, respectively. In eukaryotes, cellular organelles such as mitochondria, endoplasmic reticulum or endosomes are also surrounded by membranes. The chemical scaffold of these membranes is a bilayer of lipid molecules, that hosts small hydrophobic components such as vitamins, quinones, and pigments, as well as very large and complex membrane proteins (MP). The mass percentage of proteins in natural membranes varies between $25 \%$ in the myelin sheath to $75 \%$ in energy transducing membranes such as the mitochondrial inner membrane. ${ }^{1-3}$ This complexity makes the direct investigation of membrane protein function in native membranes difficult. To circumvent this problem, membrane proteins are purified and reinserted into membrane mimetic systems, such as protein wrapped lipid patches (nanodiscs), (supported) planar lipid bilayers or lipid vesicles. ${ }^{4}$ Here, we focus on the use of small to giant unilamellar vesicles (diameter ranging from $30 \mathrm{~nm}$ to $50 \mu \mathrm{m}$ ), called liposomes, to study membrane proteins with vectorial functions. Bordered by a single lipid bilayer, liposomes form spontaneously from dried lipids resuspended in aqueous solution.

The advent of proteoliposome studies is tightly coupled to the experimental verification of the chemiosmotic theory brought forward by Peter Mitchell in 1961., ${ }^{5,6}$ This hypothesis led to a controversy amongst research groups across continents that lasted for decades. ${ }^{7}$ A crucial experiment, positively stimulating the debate, was the coreconstitution of purple membrane Halobacterium salinarum (i.e. essentially 2D-crystallized bacteriorhodopsin) and the $\mathrm{F}_{1} \mathrm{~F}_{0}$ ATP synthase from mitochondria, showing ATP synthesis upon illumination, as described by Racker and Stoeckenius ${ }^{8}$ along with other coreconstitutions. ${ }^{9-11}$. It was the simplicity of these experiments which stood out and manifested the connection between an electrochemical gradient and ATP synthesis. The use of purified components inserted into an empty lipid bilayer ensured that no unknown factors had to be considered during the interpretation of results. Racker's method was readily picked up by many researchers to advance the mechanistic understanding of various membrane proteins. A comprehensive overview of numerous pioneering experiments is given by Etemadi. ${ }^{12}$

In general, proteins embedded in liposomes can be investigated employing the same techniques that are also used to study enzymes in solution, such as UV/VIS and fluorescence spectroscopy. Nevertheless, the signal-to-noise ratio of optical measurements is typically decreased in proteoliposomes due to light scattering. Importantly, proteoliposomes also allow for electrometric techniques to follow charge movements across the membranes, as initially developed by Drachev ${ }^{13,14}$ and colleagues for lightinducible reactions and recently adapted by Fendler and colleagues for slower reactions that require mixing techniques (SSM electrophysiology). ${ }^{15,16}$ Proteoliposomes can also be immobilized onto many different kinds of support further increasing their experimental value. ${ }^{17}$

Besides examining transmembrane transport, liposomes have been used to investigate other membrane related biological phenomena, especially membrane fusion events. Fusion of lipid bilayers is vital during virus entry into their host cells, for instance, where it is either triggered by direct virus-membrane interaction or it is receptor-mediated. Liposome studies have successfully been used to investigate virustarget cell interactions and potential inhibitors, ${ }^{18}$ mechanistic studies of virus-membrane fusion, ${ }^{19-22}$ or interaction of viral protein, receptor and antibodies in HIV. ${ }^{23}$ Furthermore, proteoliposomes have been used for NMR based structure determination of membrane proteins, wherein the membrane ensures 
proper protein folding due to the near-native environment. ${ }^{24-26}$ Finally, liposomes have been longknown as promising drug delivery systems for both hydrophobic and hydrophilic drugs alike ${ }^{27-32}$ which is a very active field of research.

In this short review, we will highlight three different aspects of current proteoliposome research. In the first, main part, we will focus on the use of liposomes for the investigation of membrane proteins, many of them being ion-translocating enzymes involved in cellular bioenergetics. As our knowledge of the interplay of cellular components vastly expanded in the last years, experimental setups of more complex systems are of increasing interest. This also involves the coreconstitution of several membrane proteins in desired orientations into the same liposomal membrane. However, robust protocols to measure or guide orientation of reconstituted proteins or to coreconstitute membrane proteins into the same membrane are still in development. We discuss current problems during reconstitution of membrane proteins and their joining into more complex systems. In the second part, we will discuss recent progress in the development of fluorescent dyes that are suitable for proteoliposome studies. Using orthogonal chemistry and different linker techniques, such dyes can be tailored to meet specific requirements, ensuring high sensitivity and temporal resolution. Finally, we briefly describe the use of giant vesicles in the bottom-up construction of synthetic cells, highlighting recent projects, in which an impressive complexity of experimental systems was achieved. 
In the seminal experiment of Racker and Stoeckenius described above, native purple bacteria were mixed with cholate-extracted mitochondrial particles (containing enriched $F_{1} F_{0}$ ATP synthase) with asolectin lipids that had been sonicated and solubilized by the bile salt sodium cholate. This mixture was then dialyzed to remove excess detergent allowing the formation of proteoliposomes capable of lightdriven ATP synthesis. ${ }^{8}$ Almost 50 years later, close variants of this very method are still powerful protocols to reconstitute membrane proteins. Over the years, several other approaches to functionally reconstitute purified MPs into liposomes were developed. Some employ organic solvents, or mechanical means such as sonication, freeze-thawing, or French-press. ${ }^{33,34}$ However, the most common methods are based on the use of detergents discussed in the next paragraphs. For an overview of different reconstitution techniques consider the pioneering reviews ${ }^{33}$ and $^{12}$, for more recent perspectives refer to. ${ }^{4,35-37}$

Generally, the process of detergent-mediated reconstitution can be divided into two main steps. First, a purified and detergent-solubilized MP is mixed with lipids. Second, the detergent is removed from the mixture, leading to the incorporation of the MP into liposomes. In the first step, the lipids are added to the solubilized MP either as fully solubilized mixed detergent-lipid micelles, or as preformed, detergentdestabilized vesicles. Detergent removal in the second step is achieved by various methods based on the critical micelle concentration (CMC) of the employed detergent. ${ }^{33}$ For small sized micelles $(<25 \mathrm{kDa}$, high CMC; e.g. sodium cholate, octyl glucoside), rapid dilution, dialysis with an appropriately sized membrane or size exclusion chromatography can be used. For detergents forming large micelles (typically very low $\mathrm{CMC}$ ), adsorption to polystyrene beads or complex formation with various cyclodextrins is used. . $^{35,38-40}$ Especially the use of cyclodextrins holds promise as different ring sizes are available that offer some specificity for certain detergents, ${ }^{38}$ e.g. allowing the selective removal of one detergent from a detergent mixture. While the exact mechanism of reconstitution by detergent removal is still not fully understood, ${ }^{36,41}$ there is agreement that at a critical detergent concentration (which depends on a variety of factors), solubilized MPs cannot be kept in a soluble state any further and either precipitate or spontaneously integrate into the present phospholipid membrane. ${ }^{4,36}$ The efficiency of the reconstitution process (fraction of the solubilized MP that incorporates into liposomes) depends on various factors, as e.g. the MP of interest itself, the type of detergent used, the initial detergent concentration, the composition of the lipid membrane, the choice of buffer and ionic strength and importantly, the method and rate of detergent removal. ${ }^{33,36}$

A special role is assigned to the lipid composition in proteoliposomes. Critical aspects for a good lipid mixture are easy liposome formation, preservation of enzyme activity and tightness of the liposomes towards leakage of protons or other ions. For many membrane proteins, a (rather crude) lecithin (phosphatidylcholine (PC)) extract of soybean has been successfully applied. In this extract, next to PC, phosphatidylethanolamine (PE), and the negative lipid phosphatidyl inositol (PI) are the other main components. Although both PC and PI are not found in bacteria, the extract has been successfully used for many prokaryotic membrane proteins. In addition, natural extracts from bacteria, e.g. from Escherichia coli or mixtures from synthetic lipids are used. Tsai and Miller have convincingly shown that mixtures of synthetic lipids are much tighter towards proton leakage compared to a polar extract of $E$. coli lipids. ${ }^{42}$ Although being outside of the scope of this review, it is noteworthy that the correct lipid composition can have a direct impact on the protein activity as briefly described in the following few examples. Non-bilayer lipids such as PE were shown to stimulate the activity of secondary transporters 
(e.g. Lyp1 of Saccheromyces cerevisiae). ${ }^{43}$ Further, the head groups of lipids, especially of anionic lipids, are responsible for the topology and the regulation of conformational dynamics of transporters by interacting with the transport proteins. ${ }^{44-48}$ The importance of negatively charged lipids, especially cardiolipin, for the activity and stability of bacterial and mitochondrial respiratory (super)complexes has also been described. ${ }^{49-51}$

The impact of lipids on the reconstitution process has been studied for some proteins, e.g. $\mathrm{Na}^{+} / \mathrm{K}^{+}-$ ATPase. ${ }^{22-56}$ De Lima Santos et al. proposed that the lipids surrounding the MP, as well as the physical state of the lipid environment as e.g. its fluidity, have a stabilizing effect on MPs. ${ }^{52}$ Longer saturated fatty acyl chains decreased membrane fluidity leading to activity loss of the MP. Thus, phospholipid mixtures that contribute to membrane fluidity (higher fractions of short-chain or unsaturated fatty acyl chains) can reduce activity loss. ${ }^{22,53,55,57}$ Further excellent studies, in which many of these parameters have been described, were published for bacteriorhodopsin and ATP synthase by Paternostre, Rigaud, Levy and colleagues, as well as for LacS by Knol, Poolmann and colleagues (see Table 1 and references therein as well as Lichtenberg et al). ${ }^{58}$ These studies show that the lipid composition can affect both the reconstitution yield and the orientation of the protein in the membrane (see below). A final complication is the natural asymmetry of lipid composition in the two leaflets of the bilayer as observed in eukaryotes and prokaryotes ${ }^{59-61}$ and first protocols for the generation of asymmetric liposomes have been described. ${ }^{62,63}$

In contrast to natural membranes, proteoliposomes contain much fewer proteins ( $<5 \%$ of lipid weight), as higher amounts of protein often negatively affect the reconstitution process. An interesting approach to tackle this problem is the GreCon method, in which the solubilized protein is placed onto a sucrose density gradient with increasing concentrations of cyclodextrin and detergent destabilized liposomes. During centrifugation, the detergent is gradually replaced by lipids, yielding liposomes with very high protein content, even triggering 2D-cristallization. ${ }^{64}$ In the density gradient, proteoliposomes and empty liposomes migrate differently and are visible as opaque bands allowing their facile separation. Such proteoliposomes have been successfully used for electron tomography imaging using large membrane complexes ${ }^{65}$, but have not yet been tested for transport measurements.

In recent years, peptides mimicking the properties of nanodiscs, ${ }^{66} \mathrm{i}$.e. embedding the membrane protein in small lipid bilayer discs surrounded by a scaffold protein, have been described ${ }^{67-69}$ While these have the advantage over traditional nanodiscs that their size can be modulated by varying the peptide to lipid ratio, they share the common drawback that they cannot be used to extract protein from native membranes, making the prior use of detergent necessary. A membrane protein extraction method not requiring any detergent is based on the use of styrene maleic acid (SMA) lipid particles (SMALPs), which has been successfully employed to purify ${ }^{70,71}$ and also functionally reconstitute MPs into lipid bilayers. ${ }^{72-}$

${ }^{76}$ Recent examples are the purification and reconstitution of cytochrome coxidase from Saccharomyces cerevisiae $^{75}$ and of a plant sodium/proton antiporter. ${ }^{76}$ Although not without downside (the solubilization properties of SMAs are $\mathrm{pH}$-dependent), ${ }^{77}$ these novel molecules are valuable gadgets in the toolbox of membrane protein biochemists.

\section{The problem of protein orientation}

In cells, insertion of membrane proteins in membranes is thought to happen co-translationally and the final orientation of the protein is fixed during insertion and remains static (see ${ }^{78}$ for a recent discussion on the topic). Unfortunately, this is not the case during membrane protein reconstitution into liposomes 
as no translational machinery or chaperones are present that help to insert membrane proteins into the liposomal bilayer. ${ }^{79,80}$

The relative orientation of the inserted MP strongly affects functional studies. As liposomes typically contain many copies of the MP in a random orientation, hundreds of different proteoliposome populations are formed during a single reconstitution process, causing a strong heterogeneity in the experimental system (see figure 1B). In some cases, functional unidirectionality can be imposed over random orientation of the MPs by using substrates which are unable to penetrate the membrane (e.g. ATP, NADH, cytochrome $c$ ), but in others, the substrate binding site is located in the hydrophobic part of the membrane and, hence, both populations are stimulated (e.g. quinone-coupled enzymes). Alternatively, membrane-impermeable inhibitors can be used, which selectively inhibit one enzyme population. ${ }^{81}$ In a worst-case scenario, the reconstitution method yields unidirectional insertion, but in the non-preferred orientation (e.g. substrate binding site on the inside), complicating functional experiments. The orientation of MPs is not only important for primary ion pumps but has to be considered as well for secondary transport proteins. While these can often catalyze transport of their substrates in both directions, the affinities for the substrate might be different on either side of the membrane, a situation that severely complicates the quantitative interpretation of experimental results. The difficulties imposed by uncontrolled orientation are even more pronounced if the coupled activity of two or more MPs coreconstituted in the same liposomal membrane is investigated (see Table 1).

The orientation of reconstituted MPs is difficult to predict and even harder to influence, and it seems to be essentially unique for each protein and specific set of reconstitution technique. ${ }^{36}$ Over the past decades, however, several studies have accumulated knowledge on protein orientation (see table 1). Many reports describe the use of bacteriorhodopsin or proteorhodopsin, which are good models for monomeric membrane proteins with no soluble domain, but inadequate as models for large multisubunit membrane proteins or membrane proteins harboring large soluble domains. A prerequisite for the investigation of MP orientation in liposomal membranes is a reliable assay to determine the ratio of the two possible populations. If feasible, orientation can be assessed via a functional assay that is able to discriminate the relative contribution of both populations. As an example, the orientation of respiratory complex $\mathrm{I}$ in liposomes can be determined by measuring $\mathrm{NADH}$ :hexaammineruthenium oxidoreductase activity that can be spectroscopically followed at $340 \mathrm{~nm}$. If $\mathrm{NADH}$, which is membraneimpermeable, is added to liposomes, only the population with the NADH binding site oriented towards the outside will contribute to the activity. Upon solubilization of the proteoliposomes with detergent, all complex I molecules will contribute to the activity. Setting both activities in relation allows for estimation of the orientation of complex I in the liposomes. ${ }^{82}$ However, care has to be taken in such approaches, as detergents often affect turnover activities of enzymes. Furthermore, if the measured activity is independent of the presence of the membrane, non-incorporated enzyme also contributes to the activity. A different method that has been used to determine orientation of proteo/bacteriorhodopsin, is the use of proteases which will only digest MP domains accessible from the outside of the liposomes due to their inability to cross the lipid bilayer. The cleavage pattern can then be analyzed by SDS-PAGE, Western blot or mass spectrometry. ${ }^{83-85}$ However, this cannot be considered as a general approach, since cleavage patterns are expected to become increasingly complex with larger proteins, and proteolysis might be incomplete. A special case is the $F_{1} F_{0}$ ATP synthase, in which those hydrophilic $F_{1}$ head group that are located on the outside of the liposomes can be specifically stripped off using defined buffer conditions. ${ }^{86}$ Yet another approach, often used for secondary antiporters, is based on the selective labelling of cysteine residues from the outside by a membrane impermeable thiol- 
reactive compound. This is followed by complete labelling with membrane permeable biotin-maleimide that can later be detected by Western-blot analysis. ${ }^{87-89}$ Further attempts to determine orientation of MPs reconstituted into liposomes can be found in Table 1.

Over the years, it has been found that numerous parameters can affect enzyme orientation during reconstitution. De Lima Santos et al. report that at a slow detergent removal rate, liposome formation precedes protein incorporation into liposomes (leading to a more unidirectional incorporation of the $\mathrm{MP}$ ), while liposome formation and protein incorporation happen simultaneously with fast detergent removal (resulting in a random orientation of MPs). ${ }^{52} \mathrm{Knol}$, Poolman and colleagues found a similar behavior for LacS, including further differences depending on the detergent used for reconstitution. ${ }^{87}$ If unidirectional orientation is not desirable, repetitive freeze/thaw cycles were shown to randomize

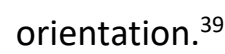

In general, experiments have shown that orientation seems to be more uniform when the MPs are reconstituted into preformed, partially detergent-solubilized liposomes..$^{41,90-92} \mathrm{~A}$ rationale behind this observation is that the most hydrophilic domain will be least efficient in crossing the bilayer, and the protein will insert with its most hydrophobic side first. ${ }^{41}$ However, experiments with cytochrome $c$ oxidases show that the hydrophilic extramembraneous cytochrome $c$-binding domain ( $25 \mathrm{kDa})$ of subunit II is not sufficient to promote more asymmetry than a 70:30 ratio. ${ }^{93} \mathrm{~F}_{1} \mathrm{~F}_{0}$ ATP synthase, on the other hand, with its soluble $350 \mathrm{kDa} \mathrm{F}_{1}$ head group, has been reported to incorporate $>95 \%$ with its head piece towards the outside with a similar reconstitution protocol ${ }^{86}$. In proteins such as $b R$ and $p R$, where no large soluble domain is present, the interaction of the surface charge of the proteins and liposomes seems to play a role. ${ }^{85,94}$ Tunuguntla et al. hold the asymmetry of charge distribution of $p R$, i.e. an overall positive charge at the $\mathrm{C}$-terminus and a negative charge at the $\mathrm{N}$-terminus, responsible for the lipidcharge dependent orientation of $\mathrm{pR}$ in liposomes. Through the use of either positively or negatively charged lipids in their liposomes, the $\mathrm{N}$ - or the $\mathrm{C}$-terminus could be attracted towards the liposomal membrane, respectively, promoting a unidirectional orientation of $\mathrm{pR} .{ }^{85}$

In one of the very few attempts to actively influence orientation, Ritzmann et al. recently showed that fusion domains can guide orientated insertion of $\mathrm{pR}$ into liposomes. ${ }^{95}$ By genetic engineering, GFP and mCherry were added to the $\mathrm{C}$-terminus or to the $\mathrm{N}$-terminus as fusion domains, respectively. The resulting fusion proteins pumped protons across the liposomal membrane in opposite directions upon reconstitution. This elegant method is unique in the sense that both orientations can be chosen by attaching a fusion domain on either end of the protein and is a promising approach for small proteins with no soluble domain. Whether the addition of a GFP is sufficient to orient larger membrane proteins remains to be determined. Other approaches for guided orientation employed Ni-NTA-functionalized beads to immobilize His-tagged MPs prior to reconstitution, ${ }^{96-98}$ a method also used to form planar bilayers for AFM studies. ${ }^{99,100}$ The liposomal membrane was formed de novo between the immobilized MPs either around the bead-support, ${ }^{96}$ or the beads were suggested to force unidirectional orientation because they were too big to be incorporated into the newly formed liposomes. ${ }^{97,98}$ However, a more thorough characterization of these methods, e.g. regarding membrane leakiness, is required. Taken together, despite identification of several parameters that influence orientation of a MP in liposomes, there is still no general method to reconstitute MPs independently of all these parameters. The rather unpredictable effect of the lipid composition on the yield and on the orientation displays a major problem, as the effect of different lipid compositions on protein activity is a frequent aspect of research. A general method for guided orientation of membrane proteins independent of the lipid composition is highly desirable. Approaches, in which orientation is guided by steric constraints might display a 
promising tool that has to be further developed in the future. ${ }^{95-98}$ Robust and easy to implement methods for the quantitative determination of incorporation yield and relative protein orientation are required to compare established and develop new reconstitution protocols, e.g. only a small subset of detergents have been used in reconstitution.

\section{Coreconstitution of Membrane Proteins}

The incorporation of different MPs into the same liposomal membrane is called coreconstitution and is desirable for several reasons. The small interior volume of liposomes leads to quick accumulation or depletion of the transported substrate, which does not allow for long steady-state measurements and thus complicates quantitative interpretation of the data. For instance, if a membrane potential is required for the transport process, often a potassium/valinomycin diffusion potential is used that quickly exhausts due to the rapid change of the internal $\mathrm{K}^{+}$concentration. Furthermore, as our understanding of biological processes increases, the interplay of different proteins at the molecular level becomes an important field of research. An impressive example of cooperating enzymes are the members of the respiratory chain which have been shown to form different supercomplexes in mitochondria. ${ }^{101,102}$ Functional measurements comparing kinetics and efficiencies between individual complexes or multiple complexes arranged in a supercomplex are necessary to understand the functional relevance of such supramolecular arrangements. ${ }^{103,104}$

There are relatively few reports on the coreconstitution of more than one type of membrane protein in the same liposomal membrane. Most work has been published on the coreconstitution of ATP synthase together with proton pumps such as bacteriorhodopsin, cytochrome $b o_{3}$ ubiquinol oxidase and cytochrome $c$ oxidase, which energize the liposomal membrane with an electrochemical potential. Such systems have been recently extended by the addition of peripheral membrane proteins. Biner et al. added trypanosomal alternative oxidase to proteoliposomes containing coreconstituted ATP synthase from E. coli and mitochondrial complex I to generate a minimal respiratory chain. ${ }^{105}$ Furthermore, ATP synthase has been used as a constant generator of proton motive force for several proton dependent secondary transporters, such as $\mathrm{Na}^{+} / \mathrm{H}^{+}$antiporter ${ }^{106,107}$ and glutamate transporter. ${ }^{108} \mathrm{An}$ alternative way to regenerate ATP from ADP and phosphate was recently shown in a synthetic metabolic network consisting of coreconstituted $\operatorname{ArCD}$ and OpuA as well as soluble proteins $\operatorname{ArcA}, B$ and $C$ entrapped in the vesicle lumen. In this complex network, ArcA - D couple the breakdown of arginine to the regeneration of ATP which is then used by OpuA for glycine betaine transport which regulates the internal osmotic balance of the vesicles. ${ }^{109}$ Non-transport related processes can also be studied by coreconstitution such as the chaperone activity of the membrane protein YidC on the folding of LacY. ${ }^{110}$ Further examples of coreconstitutions are given in Table 1. In all these examples, both types of integral membrane proteins have been reconstituted in parallel. However, given the individual requirements of every MP for optimal reconstitution and orientation, it has to be assumed that these coreconstitutions were far from being optimal. ${ }^{8,111,112}$

One way to resolve this problem is to split the coreconstitution into two steps. First, either protein of interest is reconstituted under optimal conditions individually, followed by fusion of the two populations. Successful functional coreconstitution of two MPs by fusion was first reported using a minimal SNARE machinery that fused liposome populations containing either $\mathrm{F}_{1} \mathrm{~F}_{0}$ ATP synthase or $b o_{3}$ oxidase. ${ }^{113}$ The same enzymes have also been successfully coreconstituted using fusion of oppositely charged proteoliposome populations. ${ }^{114,115}$ However, the latter method requires the use of non-natural positively charged lipids, limiting the free choice of the lipid composition. Alternative techniques which 
have been used for "pure" liposome fusion are coiled-coil forming peptides ${ }^{116}$ as well as complementary DNA strands. ${ }^{117,118}$ However these methods have not yet been tested with MP containing liposomes. ${ }^{119}$

From the above considerations on orientation and coreconstitution experiments, it is obvious that the relative number of MPs reconstituted (stoichiometry) and the distribution of orientation of these MPs is of high importance for quantitative interpretations. Given the various parameters influencing reconstitution efficiency and orientation, this seems an almost insuperable obstacle. A ray of hope was provided by Raschle et al. with a method that ensures a 1:1 reconstitution stoichiometry of MPs. Using maleimide chemistry, complementary DNA molecules were attached to a unique cysteine of individual VDAC populations ${ }^{120}$. Upon DNA hybridization, the two populations form a stable complex that can be purified and reconstituted. This technique should be applicable to any MP and using DNA linkers of appropriate lengths might not only ensure the correct stoichiometry, but also correct relative orientation of the reconstituted proteins. Alternatively, proteins can be genetically linked by creating a fusion construct that can be cleaved via proteases, as was used in the coreconstitution of SecYEG and YidC in a 1:1 stoichiometry. ${ }^{121}$

\section{Rational design of fluorescent dyes to follow enzyme function}

As mentioned in the introduction, many different methods have been successfully used to follow chemical reactions in proteoliposomes, ranging from fast techniques such as absorption spectroscopy or electrometry, over luminescence (ATP detection) to slow methods such as micro electrodes, NMR, or uptake/release of isotope labeled substrates. ${ }^{122-125}$ Probably the best combination of high sensitivity and high temporal resolution is found in fluorescent dyes which are able to detect a variety of reactions such as the change of proton or other ion concentrations or the presence of a membrane potential. Some of these dyes are membrane impermeable and have to be entrapped inside the liposomes (and the nonincorporated dye has to be removed) while others can be added from the outside, where they typically interact with the membrane. These latter, hydrophobic dyes are mainly used for the detection of proton gradients (e.g. ACMA, acridine orange) ${ }^{112,126-129}$ or membrane potentials (e.g. oxonol VI, TMRE, VoltageFluors) ${ }^{130-134}$ and do not directly report the translocated substrates.

In the following, we focus on membrane-anchored fluorescent probes that offer several advantages over entrapped dyes. A prototype of such a lipid anchored dye is obtained by the reaction of an aminereactive carboxyfluorescein derivative with phosphatidylethanolamine, first reported in 1984 by Thelen et al. ${ }^{135}$ Such lipophilic probes have been mostly used in vivo ${ }^{136-141}$ or to characterize different membrane properties. ${ }^{142}$ Recently, Kemmer et al. have coupled the ratiometric $\mathrm{pH}$ sensitive dyes pHrodo or SNARF to phosphatidylethanolamine, which in contrast to fluorescein increase fluorescence upon acidification. Notably, they found a significant increase of the apparent $\mathrm{pK}_{\mathrm{a}}$ of the lipid coupled dyes in comparison to their soluble counterparts, an effect that is likely related to the close proximity of the dye to the membrane. ${ }^{143,144}$ To avoid this $\mathrm{pK}_{\mathrm{a}}$ shift, a linker can be introduced between the fluorophore and the lipophilic moiety. ${ }^{137}$

The main advantage of membrane-anchored sensors compared to soluble dyes is their efficient incorporation into the liposomes. The lipid moiety of the former ensures stable and efficient integration into the lipid bilayer which reduces the amount of potentially costly dyes that have to be used, as entrapment of freely soluble dye is an inherently inefficient procedure. ${ }^{145-150}$ Even more importantly, membrane-anchored dyes do not leak from the membrane, a problem often encountered with soluble dyes containing carboxylic acids. On the other side, an obvious drawback of lipid coupled dyes is that they are randomly distributed in both leaflets and selective removal or quenching is impossible or 
connected to the use of harsh chemicals that are often incompatible with delicate membrane proteins and their catalytic activities. ${ }^{151}$ We have recently solved this limitation by using a DNA double strand between the lipophilic anchor (cholesterol) and fluorescent moiety. Incorporation efficiency of the dye was shown to be $>90 \%$, and the outer dye is conveniently removed by a short incubation of the liposomes with DNase I and an ultracentrifugation step. In addition, the use of a DNA linker suppressed the undesired $\mathrm{pK}_{\mathrm{a}}$ shift, previously observed with dyes directly coupled to a lipid. The simple chemistry involved makes this method attractive for many different sensors and the use of DNA hybridization technology ensures a high versatility. ${ }^{152}$ In addition to these simple examples, more advanced membrane-anchored sensors rely on structural changes of environmentally sensitive DNA motifs, such as the $\mathrm{pH}$ sensitive i-Motif ${ }^{153,154}$, G-quadruplexes ${ }^{141,155,156}$, aptamers ${ }^{138}$, DNAzymes ${ }^{157}$, nanotweezers ${ }^{158,159}$ and nanoswitches ${ }^{160}$. In these, the structural changes are transformed into a fluorescent read-out by attaching fluorescence quencher or FRET pairs to the DNA, in order to detect protons, metal ions and even small solutes such as ATP. Although mostly used in vivo so far, such complex sensors could also be useful for liposomal studies.

The development of new fluorescent dyes that are photostable as well as progress in the sensitivity of microscope cameras has further stimulated the field of single-molecule techniques. Here, instead of observing the readout of an ensemble of a large number of molecules, single enzymes are monitored by fluorescence microscopy which allows to classify them into populations with different enzymatic behaviors. While such techniques have been around for many years for soluble enzymes and membrane proteins in detergent solution, ${ }^{161-164}$ their application with proteoliposomes is very limited so far. It is however thanks to single molecule experiments with soluble and liposome embedded $F_{1} F_{0}$ ATP synthase that we have such a detailed picture of the $F_{1}$ binding change mechanism. ${ }^{165}$ Apart from the ATP synthase, the groups of Jeuken and Stamou have performed single molecule proton pumping measurements with the quinol oxidase of $E$. coli $i^{162}$ and the plasmamembrane P-type ATPase ${ }^{166}$, in which the $\mathrm{pH}$ change within the lumen of small unilamellar vesicles (SUVS) was followed by fluorescent $\mathrm{pH}$ sensors. Surprisingly, in both systems they have observed long phases of enzymatic inactivity or even passive proton leakage through the protein and have attributed their findings to a sensitive enzyme regulation by the local environment (but see Berg et al. for a different finding). ${ }^{167}$ In case of the $\mathrm{bo}_{3}$ oxidase, Jeuken and colleagues combined single protein/liposome studies with electrochemical measurements by tethering the proteoliposome to a gold electrode. By applying a voltage to the electrode, electrons were directly donated via lipid embedded ubiquinone to the $b o_{3}$ enzyme. ${ }^{162}$

The challenges of fluorescent detection is to find a probe with all desired properties, such as high incorporation into vesicles, resistance to bleaching, specificity for the substrate/product, and high signalto-noise ratio. Rational design of fluorescent dyes using click-chemistry in combination with biomolecules such as DNA allow for optimization of these properties leading to improved probes for the investigation of enzyme function in proteoliposomes.

\section{Towards a synthetic cell}

In the last section, we would like to briefly touch the potential of giant unilamellar vesicles (GUVs) to study membrane protein function. In contrast to "classical" liposomes, GUVs are much larger in size (1 $-100 \mu \mathrm{m}$ ) and can directly be observed by light microscopic techniques. ${ }^{168}$ On the downside, GUVs are less robust and their preparation is less straightforward (see ${ }^{169-178}$ for literature on GUV formation). Compared to SUVs, GUVs have a vastly increased surface and inner volume that allows for the encapsulation of entire protein machineries, small vesicles or even whole bacteria, in order to mimic increasingly complex functions of living cells. ${ }^{179}$ Already in 2004, Noireaux and Libchaber ${ }^{180}$ 
demonstrated the successful in vitro transcription and translation (IVTT) of GFP within GUVs, and recently similar systems were used to produce membrane proteins directly inside GUVs, with either spontaneous ${ }^{181}$ or assisted insertion ${ }^{182}$ into the membrane. Very few examples describe the use of GUVs as replacement for SUVs in traditional vectorial transport experiments with membrane proteins. A reason for this lack of transport experiments is the less than straightforward insertion of membrane proteins into the fragile GUV membrane which is an ongoing field of research. ${ }^{114,115,168,183}$ Levy and colleagues showed successful detergent-mediated (using very small amounts of detergent) incorporation of bacteriorhodopsin which acidified the GUV lumen upon illumination and was followed by the $\mathrm{pH}$ sensitive dye pyranine. ${ }^{184}$ Biner et al. applied charged mediated fusion to insert up to three different membrane proteins reconstituted in positively charged SUV into a negatively charged GUV membrane ${ }^{119}$. Hansen et al. finally reconstituted glucose transporter GLUT1 into GUVs using hydrogelassisted swelling. Passive uptake of glucose into the GUV lumen was detected with a glucose oxidase coupled fluorescence system that was entrapped during GUV formation. ${ }^{185}$

Given their size, GUVs are also of interest in the research on synthetic or artificial cells. ${ }^{183,186,187}$ A recent example is the light-induced energization of IVTT in GUVs after entrapment of SUVs containing bacteriorhodopsin and ATP synthase, ${ }^{188}$ mimicking a cellular organelle. Lee et al. used photosystem II (PSII) and proteorhodopsin coreconstituted with ATP synthase in SUVs that can individually be stimulated by red and green light, respectively. PSII generates a pH gradient by oxidation of water on the inside of the vesicles and $\mathrm{pR}$ dissipates the gradient by outward proton pumping. These liposomes were entrapped in GUVs and, depending on the used light, ATP synthesis is either stimulated or abolished. ${ }^{189}$

Another impressive example to use GUVs as a cell-mimicking system was demonstrated by Ces and colleagues by creating a non-natural signal cascade. Passive calcium influx into the GUV lumen via $\alpha$ hemolysin activates phospholipase $\mathrm{A} 2$ that triggered liposome embedded mechanosensitive channels. The successful signal cascade was demonstrated by the release of calcein from the liposomes which can be detected as a fluorescence increase. ${ }^{190}$ Finally, Chen et al. demonstrated the bottom-up synthesis of pancreatic beta cells using GUVs. The uptake of glucose via the glucose transporter GLUT2 into the GUV lumen triggered a cascade that mediated controlled insulin release by fusion of insulin containing vesicles with the GUV membrane. Most impressively, the system was able to discriminate between normal and hyperglycemic glucose concentrations. ${ }^{191}$

As mentioned above, GUVs are not very stable and have also been shown to be susceptible for leakage. ${ }^{192,193}$ Cell-sized vesicles produced from synthetic block copolymers, so called polymerosomes ${ }^{194}$ or hybrids thereof with liposomes are improved in this regard ${ }^{186,195}$ and have successfully been used to mimic compartmentalization of the eukaryotic cell ${ }^{196}$ or to achieve spatial separation of otherwise incompatible multienzyme synthesis reactions. ${ }^{197,198}$ However, initial experiments on polymersome embedded membrane proteins have shown that enzymatic activity was decreased compared to pure lipid vesicles. ${ }^{199,200}$ Nevertheless, proton pumping by $b o_{3}$ oxidase was recently demonstrated in hybrid polymer-lipid GUVs. ${ }^{201}$ Some of these examples discussed above are depicted in Figure 2, see legend for further details.

These cell-mimetic applications greatly demonstrate the potential of giant vesicles. Importantly, a wise choice of detection method is crucial that allows high temporal resolution combined with sufficient sensitivity. To this end, photostable fluorophores are required to minimize bleaching during observation of single vesicles. To allow for prolonged observation and addition of substrates, vesicles have to be immobilized, which might have adverse effects on membrane properties such as the tightness of the membrane. Recently, experiments using microfluidics have shown formation and entrapment of GUVs in a nano-factory on a chip, ${ }^{202,203}$ which in the future might allow to create automated systems. However, 
many of the current approaches (single molecule measurements, microfluidics) require technical expertise and specialized equipment which limits the use of the techniques in other labs. In the future, robust methods with a broad application and high reproducibility are critical for the success of GUVs in the field of membrane protein research. Equivalently important is a detailed description of the data treatment. As microscopy experiments produce a large amount of data, user-friendly yet powerful analytical software is a necessary support during data analysis. 


\section{Perspective section}

(i) highlight the importance of the field

Proteoliposome research continues to be an indispensable tool for the mechanistic understanding of membrane proteins. With the advent of structure determination by cryo electron microscopy, functional measurements are becoming the rate-limiting step.

(ii) a summary of the current thinking

Development of improved methods for the precise orientation and coreconstitution of MPs into membranes are required. This is especially relevant for the bottom-up construction of artificial cells. Using fluorescent dyes with precisely tailored properties will ensure high sensitivity and temporal resolution.

(iii) a comment on future directions

Microscopy based measuring techniques applied on liposomes will further minimize the required amount of membrane proteins, enabling the investigation of eukaryotic enzymes. The use of microfluidics for the generation and manipulation of GUVs might allow a higher level of control in labon-a-chip type experiments.

\section{Acknowledgements}

We thank the members of the group for helpful discussions.

\section{Funding}

Research in the author's lab is funded by the Swiss National Science Foundation (grant No. 176154).

The authors declare no conflicts of interest. 
Figure 1:

A

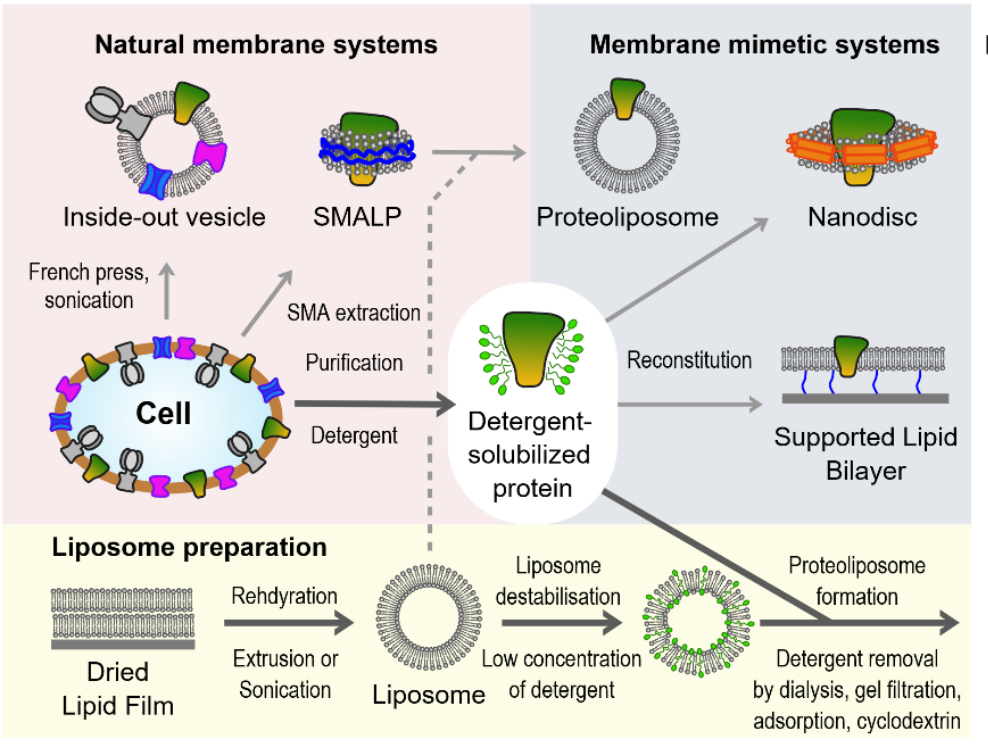

B

Proteoliposome populations after reconstitution Shown are the different populations after a 1:1 reconstitution with a 70:30 orientation preference
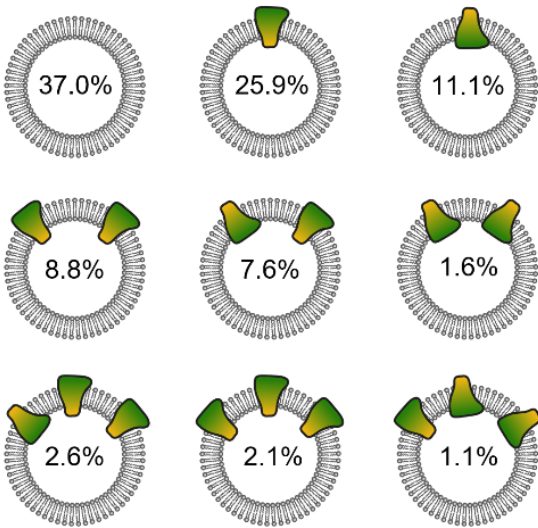

C

D

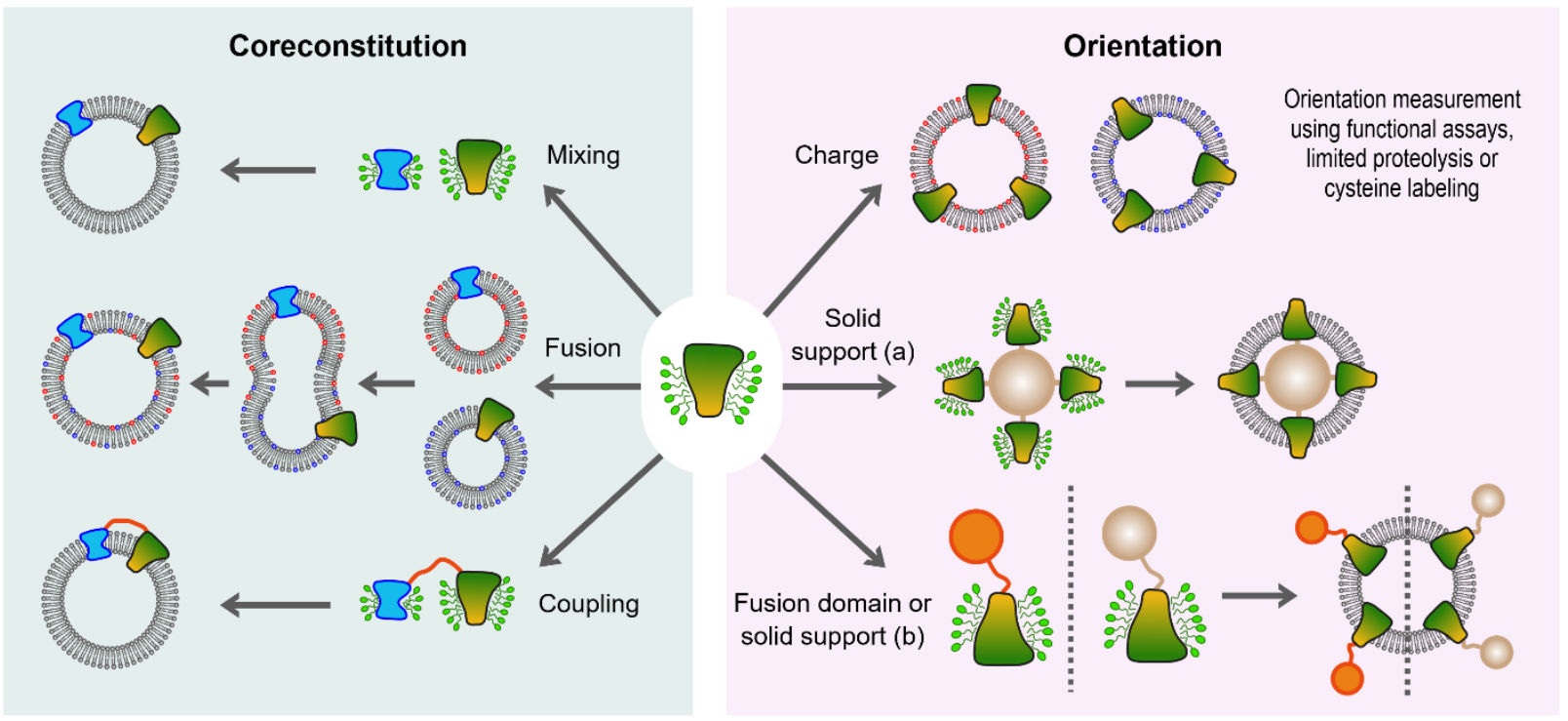

Figure 1: The ins and outs of membrane protein reconstitution

A) The general procedure for the formation of proteoliposomes is shown as well as a few alternative approaches for the in vitro study of membrane protein (MP) function. In a first step, MPs are extracted and purified from the native cell environment using detergents. In parallel, liposomes are formed by rehydration of a dried lipid film and subsequent extrusion or sonication of the vesicles. These liposomes are partially solubilized by the addition of detergents and mixed with the detergent-solubilized MP to form proteoliposomes after removal of the detergent by a variety of methods. Detergent-free extraction of MPs from the cell can be achieved by generating inside-out vesicles ${ }^{204}$ or using styrene-maleic acid (SMA) copolymers to generate SMALPs. The latter can be used for the detergent-free reconstitution of 
MPs into liposomes. ${ }^{70-76}$ If a closed compartment is not needed, detergent-solubilized MPs can also be reconstituted into planer supported lipid bilayers or nanodiscs. ${ }^{4}$

B) The calculated distribution of proteoliposome populations after reconstitution with a 1:1 liposome to protein stoichiometry and a $70 \%$ green-side out preference in orientation. Values were calculated assuming a Poisson distribution for reconstitution and a binomial distribution for orientation. Only populations $>1 \%$ are shown.

C) Coreconstitution of more than one membrane protein. Shown are coreconstitutions by a combined incubation of both MPs with liposomes, via fusion of different proteoliposome populations (e.g. chargemediated fusion, red lipids = negatively charged, blue lipids = positively charged) ${ }^{114,115}$ or via covalent/transient coupling of the MPs prior to reconstitution. ${ }^{120}$

D) Methods for the guided orientation during reconstitutions. Shown are examples of charge-controlled insertion, ${ }^{85,94}$ by coupling the MP to a solid support (a) that will be encapsulated by the liposome ${ }^{96}$ or by attaching a fusion domain ${ }^{95}$ or coupling to a solid support $(b)^{97,98}$ that will be excluded from the vesicle interior. 
Figure 2:

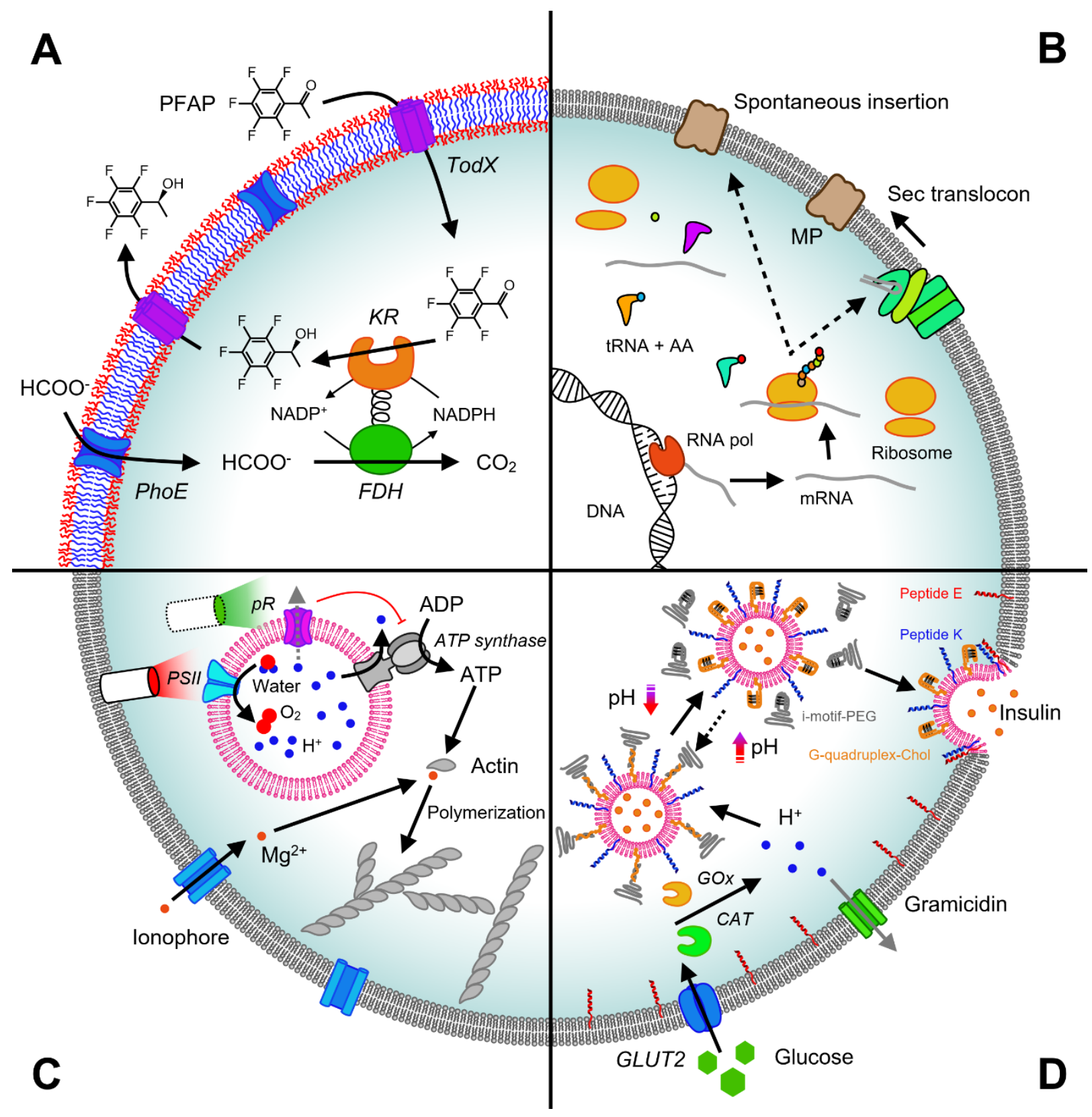

Figure 2: Applications of membrane proteins (MPs) in giant unilamellar vesicles (GUVs) and polymerosomes.

A) MPs embedded in a polymerosome membrane enables import and export of substrates and products from a synthetic reaction cell. In that cell, pentafluoracetophenon (PFAP) is transformed to (S)pentafluorophenyl ethanol ((S)-PFE) by ketoreductase (KR) inside of polymerosomes with NADPH as cofactor. NADPH is regenerated by formate dehydrogenase (FDH) which is fused to KR. As PFAP, (S)-PFE and formate do not readily diffuse across the polymerosome membrane, the selective channel protein TodX and the outer membrane pore PhoE were reconstituted in the membrane to alleviate the mass transport limitations. ${ }^{198}$

B) Membrane protein synthesis in GUVs by in vitro transcription and translation. Relevant components shown for these processes are DNA, RNA polymerase (RNA pol), the produced mRNA, ribosomes, tRNAs 
and amino acids (AA). After translation, the synthesized MP inserts either spontaneously ${ }^{181}$ into the vesicle membrane, or requires the Sec translocon ${ }^{205}$ for correct insertion. ${ }^{182}$

C) Regulated ATP synthesis promoting actin polymerization in synthetic organelles. The membrane proteins $\mathrm{F}_{1} \mathrm{~F}_{0}$ ATP synthase, photosystem II (PSII) and proteorhodopsin (pR) are coreconstituted in SUVs that are entrapped in GUVs. Red light stimulates PSII leading to oxidation of water and thus acidification of the SUV interior. Acidification leads to a proton gradient across the SUV membrane energizing ATP synthesis in the GUV lumen that is used to polymerize actin. On the other hand, green light stimulates proton export from the SUV lumen by proteorhodopsin, abolishing the proton gradient. Consequently, synthesis of ATP is stopped and actin polymerization is interrupted. ${ }^{189}$

D) Design of minimal pancreatic beta cell. The glucose transporter GLUT2 is reconstituted into the membrane of GUVs containing SUVs with encapsulated insulin. After uptake by GLUT2, glucose is oxidized by glucose oxidase (GOX) and catalase (CAT), leading to an acidification of the GUV lumen. This $\mathrm{pH}$ drop leads to the dehybridization of DNA double strand anchored to the SUV outer membrane by the formation of a $\mathrm{pH}$-sensitive motif, exposing the fusogenic peptide $\mathrm{K}$ on the outer SUV membrane. This allows fusion of the SUV with the GUV membrane via peptide E/K interaction, leading to the release of the encapsulated insulin. Gramicidin present in the GUV membrane modulates the $\mathrm{pH}$ response and allows to discern between normal and hyperglycemic conditions. ${ }^{191}$

Figures $2 A-D$ are adapted from the respective publications. 


\section{Table 1:}

Non-exhaustive list of different studies with a focus on coreconstitution of MPs or orientation of MPs. For the latter, studies are further distinguished between simply investigating orientation under one or several different conditions and actively influencing orientation by different means. Studies are grouped according to the investigated MP and the origin of the MP and the studied parameter is indicated. A short summary of the study is provided in the comments row.

\begin{tabular}{|c|c|c|c|c|}
\hline Membrane Protein & Organism & Study & Comments & References \\
\hline \multirow[t]{3}{*}{$\mathrm{aa}_{3} \mathrm{CcO}$} & $\begin{array}{l}\text { Rhodobacter } \\
\text { sphaeroides }\end{array}$ & Coreconstitution & $\begin{array}{l}\text { Coreconstitution of } \mathrm{aa}_{3} \mathrm{CcO} \text { with } \mathrm{F}_{1} \mathrm{~F}_{0} \text { ATP synthase (E. coli) or spinach } \\
\text { ATP synthase. }\end{array}$ & 112 \\
\hline & & Investigating orientation & $\begin{array}{l}70 \text { - } 80 \% \text { CcO was found with soluble domain of subunit II carrying the } \\
\text { cytochrome c-binding site towards the outside of the liposomes. } \\
\text { Functional unidirectionality can be imposed over orientation of the MP } \\
\text { in the liposomal membrane by providing cytochrome } c \text { and electrons only } \\
\text { on one side of the membrane. }\end{array}$ & 93 \\
\hline & $\begin{array}{l}\text { Paracoccus } \\
\text { denitrificans }\end{array}$ & Influencing orientation & $\begin{array}{l}\text { MP was immobilized on Ni-NTA-functionalized silica nanoparticles for } \\
\text { orientated encapsulation into liposomes (bead on outside of } \\
\text { proteoliposome). }\end{array}$ & 97,98 \\
\hline ArcD2 & $\begin{array}{l}\text { Lactococcus } \\
\text { lactis }\end{array}$ & Coreconstitution & Coreconstitution with OpuA and soluble proteins ArcA, B and C (L. lactis) & 109 \\
\hline \multirow[t]{3}{*}{ bacteriorhodopsin } & $\begin{array}{l}\text { Halobacterium } \\
\text { salinarum }\end{array}$ & Coreconstitution & Coreconstitution with ATP synthase from bovine heart mitochondria. & 8 \\
\hline & & Investigating orientation & Only slight preference for inside-out was detected. & 206 \\
\hline & & & $\begin{array}{l}\text { Orientation in proteoliposomes was shown to depend on lipid } \\
\text { composition of the liposomes, } \mathrm{pH} \text { value, ionic strength, \& membrane } \\
\text { curvature (in order of decreasing influence on orientation). }\end{array}$ & 80 \\
\hline $\mathrm{Ca}^{2+}-\mathrm{P}-\mathrm{ATPase}$ & $\begin{array}{l}\text { rabbit } \\
\text { sarcoplasmic } \\
\text { reticulum }\end{array}$ & Investigating orientation & $\begin{array}{l}\text { Unidirectional orientation with } 80 \%-100 \% \text { of the cytoplasmic domain } \\
\text { facing outwards was observed, depending on the rate of detergent } \\
\text { removal }\end{array}$ & 207 \\
\hline \multirow[t]{5}{*}{$\begin{array}{l}\text { cytochrome } \mathrm{bo}_{3} \\
\text { ubiquinol oxidase }\end{array}$} & E. coli & Coreconstitution & $\begin{array}{l}\text { coreconstitution of } b o_{3} \text { oxidase with } \mathrm{F}_{1} \mathrm{~F}_{0} \text { ATP synthase (E. coli) via charge- } \\
\text { mediated fusion of liposomes to GUVs }\end{array}$ & 114,115 \\
\hline & & & $\begin{array}{l}\text { coreconstitution of } b_{3} \text { oxidase with } \mathrm{F}_{1} \mathrm{~F}_{0} \text { ATP synthase }(E \text {. coli) or spinach } \\
\text { ATP synthase }\end{array}$ & 112 \\
\hline & & & $\begin{array}{l}\text { coreconstitution of } b o_{3} \text { oxidase with } \mathrm{F}_{1} \mathrm{~F}_{0} \text { ATP synthase (E. coli) via SNARE- } \\
\text { mediated fusion }\end{array}$ & 113 \\
\hline & & Investigating orientation & $72-77 \%$ to pump protons out of liposomes & 162,167 \\
\hline & & & $\begin{array}{l}\text { Unidirectional orientation is reported using a reconstitution method } \\
\text { based on Rigaud et } a .^{33} \text { However, no biochemical proof of } \\
\text { unidirectionality is provided. }\end{array}$ & 208 \\
\hline $\begin{array}{l}\text { cytochrome } b \text { - } \\
563 / c-554(Q b c)\end{array}$ & $\begin{array}{l}\text { Synechococcus } \\
6716\end{array}$ & Coreconstitution & Coreconstitution with $\mathrm{H}^{+}$-ATP synthase from Synechococcus 6716. & 111 \\
\hline \multirow[t]{2}{*}{$\mathrm{F}_{1} \mathrm{~F}_{0}$ ATP synthase } & E. coli & Coreconstitution & $\begin{array}{l}\text { Refer to cytochrome } b_{3} \text { ubiquinol oxidase. Further coreconstitutions } \\
\text { with } \mathrm{Na}^{+} / \mathrm{H}^{+} \text {antiporters (Thermus thermophilus NapA and human } \\
\mathrm{NHA2} \text { ), rat VGLUT2 as well as mitochondrial complex I from Bos Taurus } \\
\text { together with alternative oxidase from trypanosoma brucei brucei. }\end{array}$ & $105-108$ \\
\hline & & Investigating orientation & $>97 \%$ of $F_{1}$ facing outwards was shown. & 86 \\
\hline LacS & $\begin{array}{l}\text { Streptococcus } \\
\text { thermophilus }\end{array}$ & Investigating orientation & $\begin{array}{l}\text { Different detergents \& detergent concentrations were evaluated as well } \\
\text { as different rates of detergent removal. Unidirectional inside-out } \\
\text { orientation is reported for reconstitution with Triton X-100 and random } \\
\text { orientation for reconstitution with n-Dodecyl } \beta \text {-D-maltoside. }\end{array}$ & 87,209 \\
\hline $\begin{array}{l}\text { large-conductance } \\
\text { calcium- and } \\
\text { voltage-activated } \\
\text { potassium channel } \\
\text { (BK) }\end{array}$ & Homo sapiens & Investigating orientation & $70 \%$ inside-out orientation of MP is reported. & 210 \\
\hline $\begin{array}{l}\text { mechanosensitive } \\
\text { channel of small } \\
\text { conductance } \\
\text { (MscS) }\end{array}$ & $\begin{array}{l}\text { bacterial (no } \\
\text { further } \\
\text { statement } \\
\text { made) }\end{array}$ & Investigating orientation & $\begin{array}{l}\text { Unidirectional incorporation is reported based solely on } \\
\text { electrophysiological results; no physical evidence is provided. Two ion } \\
\text { channel reconstitution methods based on dehydration/rehydration of } \\
\text { liposomes in presence of MP were tested. }\end{array}$ & 211 \\
\hline $\mathrm{Na}^{+} / \mathrm{K}^{+}-\mathrm{P}$-ATPase & $\begin{array}{l}\text { Electrophorus } \\
\text { electricus or } \\
\text { Squalus } \\
\text { acanthias }\end{array}$ & Investigating orientation & $\begin{array}{l}\text { Functional unidirectionality was imposed over orientation of MP in } \\
\text { membrane by selective inhibition of one of the two orientation } \\
\text { populations with ouabain (exterior) or vanadate ions (interior). }\end{array}$ & 212,213 \\
\hline
\end{tabular}




\begin{tabular}{|c|c|c|c|c|}
\hline & $\begin{array}{l}\text { dark red outer } \\
\text { medulla of } \\
\text { kidney of adult } \\
\text { New Zealand } \\
\text { white rabbits }\end{array}$ & Investigating orientation & $\begin{array}{l}\text { Different protein-to-lipid ratios, different phospholipids and methods of } \\
\text { detergent removal were investigated. }\end{array}$ & 52 \\
\hline \multirow[t]{4}{*}{ proteorhodopsin } & $\begin{array}{l}\text { uncultured } \\
\text { Gammaproteo } \\
\text { bacterium } \\
\text { EBAC31A08 }\end{array}$ & Coreconstitution & $\begin{array}{l}\text { Coreconstitution with Spinacia oleracea PSII and Bacillus pseudofirmus } \\
\text { ATP synthase }\end{array}$ & 189 \\
\hline & & Influencing orientation & $\begin{array}{l}\text { Interaction of MP with the surface of the liposomes was shown to dictate } \\
\text { orientation. The surface charge of liposomes was modulated to } \\
\text { prearrange orientation. }\end{array}$ & 85,94 \\
\hline & & & $\begin{array}{l}\text { MP was immobilized on Ni-NTA-functionalized silicate beads for } \\
\text { orientated reconstitution (bead on outside of proteoliposome). }\end{array}$ & 214 \\
\hline & & & $\begin{array}{l}\text { Fusion domains were reported to guide the orientated insertion of } \\
\text { proteorhodopsin into liposomes. }\end{array}$ & 95 \\
\hline $\begin{array}{l}\text { various }\left(\mathrm{Ca}^{2+}-\mathrm{P}-\right. \\
\text { ATPase, } \mathrm{H}^{+}-\mathrm{F}- \\
\text { ATPase, LacS) }\end{array}$ & various & Investigating orientation & $\begin{array}{l}\text { More uniform orientation of MPs was observed in the reconstituted } \\
\text { liposomal bilayer when reconstituted into preformed, detergent- } \\
\text { destabilized liposomes. }\end{array}$ & $81,87,90,91,215$ \\
\hline $\begin{array}{l}\text { voltage-dependent } \\
\left.\mathrm{K}^{+} \text {channel ( } \mathrm{K}_{\mathrm{v}} \mathrm{AP}\right)\end{array}$ & $\begin{array}{l}\text { Aeropyrum } \\
\text { pernix }\end{array}$ & Influencing orientation & $\begin{array}{l}\text { Ni-NTA-functionalized beads were used as membrane organization } \\
\text { centers during bilayer reconstitution (bead in proteoliposome; bSUM). }\end{array}$ & 96 \\
\hline YidC & $\begin{array}{l}\text { Escherichia } \\
\text { Coli }\end{array}$ & Coreconstitution & Coreconstitution with LacY and SecYEG as a fusion construct & 110,121 \\
\hline
\end{tabular}




\section{References}

1. Stillwell, W. Introduction to Biological Membranes. An Introd. to Biol. Membr. 3-15 (2016). doi:10.1016/b978-0-444-63772-7.00001-4

2. Alberts, B. et al. Molecular Biology of the Cell. (Garland Science, 2017). doi:10.1201/9781315735368

3. Nelson, D. L., Lehninger, A. L. \& Cox, M. M. Lehninger Principles of Biochemistry. (W. H. Freeman, 2008).

4. Shen, H. H., Lithgow, T. \& Martin, L. L. Reconstitution of membrane proteins into model membranes: Seeking better ways to retain protein activities. Int. J. Mol. Sci. 14, 1589-1607 (2013).

5. Mitchell, P. Chemiosmotic Coupling in Oxidative and Photosynhetic Phosphorylation. Biol. Rev. 41, 445-502 (1966).

6. Mitchell, P. Coupling of phosphorylation to electron and hydrogen transfer by a chemi-osmotic type of mechanism. Nature 191, 144-191 (1961).

7. Prebble, J. Peter Mitchell and the ox phos wars. Trends Biochem. Sci. 27, 209-12 (2002).

8. Racker, E. \& Stoeckenius, W. Reconstitution of purple membrane vesicles catalyzing light-driven proton uptake and adenosine triphosphate formation. J. Biol. Chem. 249, 662-3 (1974).

9. Hinkle, P. C., Kim, J. J. \& Racker, E. Ion transport and respiratory control in vesicles formed from cytochrome oxidase and phospholipids. J. Biol. Chem. 247, 1338-1339 (1972).

10. Racker, E. Reconstitution of a calcium pump with phospholipids and a purified $\mathrm{Ca}++-$ adenosine triphosphatase from sacroplasmic reticulum. J. Biol. Chem. 247, 8198-200 (1972).

11. Eytan, G. D., Persson, B., Ekebacke, A. \& Rydström, J. Energy-linked nicotinamide-nucleotide transhydrogenase. Characterization of reconstituted ATP-driven transhydrogenase from beef heart mitochondria. J. Biol. Chem. 262, 5008-5014 (1987).

12. Etemadi, A. H. Functional and orientational features of protein molecules in reconstituted lipid membranes. Advances in lipid research 21, (ACADEMIC PRESS, INC., 1985).

13. Drachev, L. A., Kaulen, A. D., Ostroumov, S. A. \& Skulachev, V. P. Electrogenesis by bacteriorhodopsin incorporated in a planar phospholipid membrane. FEBS Lett. 39, 43-45 (1974).

14. Drachev, L. A. et al. Direct measurement of electric current generation by cytochrome oxidase, H+-ATPase and bacteriorhodopsin. Nature 249, 321-324 (1974).

15. Bazzone, A., Barthmes, M. \& Fendler, K. SSM-Based Electrophysiology for Transporter Research. Methods Enzymol. 594, 31-83 (2017).

16. Schulz, P., Garcia-Celma, J. J. \& Fendler, K. SSM-based electrophysiology. Methods 46, 97-103 (2008).

17. Früh, V. et al. How to catch a membrane protein in action: A review of functional membrane protein immobilization strategies and their applications. Chem. Rev. 111, 640-656 (2011).

18. Smit, J. M., Waarts, B. L., Bittman, R. \& Wilschut, J. Liposomes as Target Membranes in the Study of Virus Receptor Interaction and Membrane Fusion. Methods Enzymol. 372, 374-392 (2003). 
19. Hoekstra, D. \& Klappe, K. [20] Fluorescence assays to monitor fusion of enveloped viruses. in 261-276 (1993). doi:10.1016/0076-6879(93)20088-K

20. Tuthill, T. J., Bubeck, D., Rowlands, D. J. \& Hogle, J. M. Characterization of Early Steps in the Poliovirus Infection Process : Receptor-Decorated Liposomes Induce Conversion of the Virus to Particles Characterization of Early Steps in the Poliovirus Infection Process : ReceptorDecorated Liposomes Induce Conver. J. Virol. 80, 172-180 (2006).

21. Whitbeck, J. C., Zuo, Y., Milne, R. S. B., Cohen, G. H. \& Eisenberg, R. J. Stable Association of Herpes Simplex Virus with Target Membranes Is Triggered by Low pH in the Presence of the gD Receptor, HVEM. J. Virol. 80, 3773-3780 (2006).

22. Vallbracht, M. et al. Structure-Function Dissection of Pseudorabies Virus Glycoprotein B Fusion Loops. J. Virol. 92, 1-26 (2017).

23. Zhukovsky, M. A. et al. Thermal stability of the human immunodeficiency virus type 1 (HIV-1) receptors, CD4 and CXCR4, reconstituted in proteoliposomes. PLoS One 5, (2010).

24. Yeliseev, A. Expression and Preparation of a G-Protein-Coupled Cannabinoid Receptor CB2 for NMR Structural Studies. Curr. Protoc. Protein Sci. 96, 1-21 (2019).

25. Shi, C. et al. Structure and Dynamics of the Rhomboid Protease GlpG in Liposomes Studied by Solid-State NMR. J. Am. Chem. Soc. 141, 17314-17321 (2019).

26. Zhou, S. et al. Solution NMR structure of yeast Rcf1, a protein involved in respiratory supercomplex formation. Proc. Natl. Acad. Sci. U. S. A. 115, 3048-3053 (2018).

27. Patel, M. M. \& Patel, B. M. Crossing the Blood-Brain Barrier: Recent Advances in Drug Delivery to the Brain. CNS Drugs 31, 109-133 (2017).

28. Li, X. et al. Nano carriers for drug transport across the blood-brain barrier. J. Drug Target. 25, 17-28 (2017).

29. Mittal, S., Chaudhary, A., Chaudhary, A. \& Kumar, A. Proniosomes: the effective and efficient drug-carrier system. Ther. Deliv. 11, 125-137 (2020).

30. Zylberberg, C. \& Matosevic, S. Pharmaceutical liposomal drug delivery: a review of new delivery systems and a look at the regulatory landscape. Drug Deliv. 23, 3319-3329 (2016).

31. Abu Lila, A. S. \& Ishida, T. Liposomal Delivery Systems: Design Optimization and Current Applications. Biol. Pharm. Bull. 40, 1-10 (2017).

32. Lee, Y. \& Thompson, D. H. Stimuli-responsive liposomes for drug delivery. Wiley Interdiscip. Rev. Nanomed. Nanobiotechnol. 9, (2017).

33. Rigaud, J. L., Pitard, B. \& Levy, D. Reconstitution of membrane proteins into liposomes: application to energy-transducing membrane proteins. BBA - Bioenerg. 1231, 223-246 (1995).

34. Laubinger, W. \& Dimroth, P. Characterization of the ATP Synthase of Propionigenium modesturn as a Primary Sodium Pump. Biochemistry 27, 7531-7537 (1988).

35. Rigaud, J.-L. \& Lévy, D. Reconstitution of Membrane Proteins into Liposomes. in Methods in Molecular Biology 1635, 65-86 (2003).

36. Skrzypek, R., Iqbal, S. \& Callaghan, R. Methods of reconstitution to investigate membrane protein function. Methods (2018). doi:10.1016/j.ymeth.2018.02.012

37. Seddon, A. M., Curnow, P. \& Booth, P. J. Membrane proteins, lipids and detergents: Not just a soap opera. Biochim. Biophys. Acta-Biomembr. 1666, 105-117 (2004). 
38. Degrip, W. J., Vanoostrum, J. \& Bovee-Geurts, P. H. Selective detergent-extraction from mixed detergent/lipid/protein micelles, using cyclodextrin inclusion compounds: a novel generic approach for the preparation of proteoliposomes. Biochem J 330 ( Pt 2, 667-674 (1998).

39. Geertsma, E. R., Nik Mahmood, N. A. B., Schuurman-Wolters, G. K. \& Poolman, B. Membrane reconstitution of $A B C$ transporters and assays of translocator function. Nat. Protoc. 3, 256-266 (2008).

40. Hatzi, P., Mourtas, S., Klepetsanis, P. G. \& Antimisiaris, S. G. Integrity of liposomes in presence of cyclodextrins: effect of liposome type and lipid composition. Int. J. Pharm. 333, 167-76 (2007).

41. Knol, J. PhD-Thesis - Membrane Reconstitution and Functional Analysis of a Sugar Transport System. (1999).

42. Tsai, M. F. \& Miller, C. Substrate selectivity in arginine-dependent acid resistance in enteric bacteria. Proc. Natl. Acad. Sci. U. S. A. 110, 5893-5897 (2013).

43. Klooster, J. S. Van, Cheng, T., Sikkema, H. R. \& Jeucken, A. Membrane Lipid Requirements of the Lysine Transporter Lyp1 from Saccharomyces cerevisiae. J. Mol. Biol. 432, 4023-4031 (2020).

44. Harris, N. J., Charalambous, K., Findlay, H. E. \& Booth, P. J. Lipids modulate the insertion and folding of the nascent chains of alpha helical membrane proteins. Biochem. Soc. Trans. 46, 1355-1366 (2018).

45. Martens, C. et al. Direct protein-lipid interactions shape the conformational landscape of secondary transporters. Nat. Commun. 9, (2018).

46. Mirandela, G. Di., Tamburrino, G., Hoskisson, P. A., Zachariae, U. \& Javelle, A. The lipid environment determines the activity of the Escherichia coli ammonium transporter AmtB. FASEB J. 33, 1989-1999 (2019).

47. Vitrac, H., Mallampalli, V. K. P. S., Bogdanov, M. \& Dowhan, W. The lipid-dependent structure and function of LacY can be recapitulated and analyzed in phospholipid-containing detergent micelles. Sci. Rep. 9, (2019).

48. Dowhan, W., Vitrac, H. \& Bogdanov, M. Lipid-Assisted Membrane Protein Folding and Topogenesis. Protein J. 38, 274-288 (2019).

49. Zhang, M., Mileykovskaya, E. \& Dowhan, W. Cardiolipin Is Essential for Organization of Complexes III and IV into a Supercomplex in Intact Yeast Mitochondria. J. Biol. Chem. 280, 29403-29408 (2005).

50. Paradies, G., Paradies, V., De Benedictis, V., Ruggiero, F. M. \& Petrosillo, G. Functional role of cardiolipin in mitochondrial bioenergetics. Biochim. Biophys. Acta - Bioenerg. 1837, 408-417 (2014).

51. Arnarez, C., Marrink, S. J. \& Periole, X. Molecular mechanism of cardiolipin-mediated assembly of respiratory chain supercomplexes. Chem. Sci. 7, 4435-4443 (2016).

52. Santos, H. de L., Lopes, M. L., Maggio, B. \& Ciancaglini, P. Na,K-ATPase reconstituted in liposomes: effects of lipid composition on hydrolytic activity and enzyme orientation. Colloids Surfaces B Biointerfaces 41, 239-248 (2005).

53. Mohraz, M. Reconstitution of Detergent-Solubilized Na,K-ATPase and Formation of TwoDimensional Crystals. J. Struct. Biol. 125, 76-85 (1999).

54. Cornelius, F. Modulation of Na,K-ATPase and Na-ATPase Activity by Phospholipids and Cholesterol. I. Steady-State Kinetics †. Biochemistry 40, 8842-8851 (2001). 
55. Abeywardena, M. Y., Allen, T. M. \& Charnock, J. S. Lipid-protein interactions of reconstituted membrane-associated adenosinetriphosphatases. Use of a gel-filtration procedure to examine phospholipid-activity relationships. Biochim. Biophys. Acta-Biomembr. 729, 62-74 (1983).

56. Cornelius, F., Turner, N. \& Christensen, H. R. Z. Modulation of Na,K-ATPase by Phospholipids and Cholesterol. II. Steady-State and Presteady-State Kinetics †. Biochemistry 42, 8541-8549 (2003).

57. Yeagle, P. L. \& University of Connecticut, Storrs, CT, U. The Membranes of Cells. (2016).

58. Lichtenberg, D., Ahyayauch, H. \& Goni, F. M. The mechanism of detergent solubilization of lipid bilayers. Biophys J 105, 289-299 (2013).

59. Marquardt, D., Geier, B. \& Pabst, G. Asymmetric lipid membranes: towards more realistic model systems. Membr. 5, 180-196 (2015).

60. Furse, S. \& Scott, D. J. Three-Dimensional Distribution of Phospholipids in Gram Negative Bacteria. Biochemistry 55, 4742-7 (2016).

61. Bogdanov, M. et al. Phospholipid distribution in the cytoplasmic membrane of Gram-negative bacteria is highly asymmetric, dynamic, and cell shape-dependent. Sci. Adv. 6, eaaz6333 (2020).

62. Doktorova, M. et al. Preparation of asymmetric phospholipid vesicles for use as cell membrane models. Nat. Protoc. 13, 2086-2101 (2018).

63. Markones, M. et al. Stairway to Asymmetry: Five Steps to Lipid-Asymmetric Proteoliposomes. Biophys. J. 118, 294-302 (2020).

64. Althoff, T., Davies, K. M., Schulze, S., Joos, F. \& Kühlbrandt, W. GRecon: A method for the lipid reconstitution of membrane proteins. Angew. Chemie - Int. Ed. 51, 8343-8347 (2012).

65. Blum, T. B., Hahn, A., Meier, T., Davies, K. M. \& Kühlbrandt, W. Dimers of mitochondrial ATP synthase induce membrane curvature and self-assemble into rows. Proc. Natl. Acad. Sci. U. S. A. 116, 4250-4255 (2019).

66. Denisov, I. G., Schuler, M. A. \& Sligar, S. G. Nanodiscs as a New Tool to Examine Lipid-Protein Interactions. Methods Mol. Biol. 2003, 645-671 (2019).

67. Kariyazono, H. et al. Formation of stable nanodiscs by bihelical apolipoprotein A-I mimetic peptide. J. Pept. Sci. 22, 116-122 (2016).

68. Carlson, M. L. et al. The Peptidisc, a simple method for stabilizing membrane proteins in detergent-free solution. Elife 7, 1-23 (2018).

69. Angiulli, G. et al. New approach for membrane protein reconstitution into peptidiscs and basis for their adaptability to different proteins. Elife 9, 1-20 (2020).

70. Smirnova, I. A. et al. Isolation of yeast complex IV in native lipid nanodiscs. Biochim. Biophys. Acta-Biomembr. 1858, 2984-2992 (2016).

71. Dörr, J. M. et al. The styrene-maleic acid copolymer: a versatile tool in membrane research. Eur. Biophys. J. 45, 3-21 (2016).

72. Dörr, J. M. et al. Detergent-free isolation, characterization, and functional reconstitution of a tetrameric K+ channel: The power of native nanodiscs. Proc. Natl. Acad. Sci. U. S. A. 111, 18607-18612 (2014).

73. Parmar, M. J., Lousa, C. D. M., Muench, S. P., Goldman, A. \& Postis, V. L. G. Artificial membranes for membrane protein purification, functionality and structure studies. Biochem. Soc. Trans. 44, 
877-882 (2016).

74. Broecker, J., Eger, B. T. \& Ernst, O. P. Crystallogenesis of Membrane Proteins Mediated by Polymer-Bounded Lipid Nanodiscs. Structure 25, 384-392 (2017).

75. Smirnova, I. A., Ädelroth, P. \& Brzezinski, P. Extraction and liposome reconstitution of membrane proteins with their native lipids without the use of detergents. Sci. Rep. 8, 14950 (2018).

76. Dutta, D., Esmaili, M., Overduin, M. \& Fliegel, L. Expression and detergent free purification and reconstitution of the plant plasma membrane $\mathrm{Na}+/ \mathrm{H}+$ antiporter SOS1 overexpressed in Pichia pastoris. Biochim. Biophys. Acta-Biomembr. 1862, 183111 (2020).

77. Scheidelaar, S. et al. Effect of Polymer Composition and pH on Membrane Solubilization by Styrene-Maleic Acid Copolymers. Biophys. J. 111, 1974-1986 (2016).

78. Fluman, N., Tobiasson, V. \& Von Heijne, G. Stable membrane orientations of small dualtopology membrane proteins. Proc. Natl. Acad. Sci. U. S. A. 114, 7987-7992 (2017).

79. Hegde, R. S. \& Keenan, R. J. Tail-anchored membrane protein insertion into the endoplasmic reticulum. Nat. Rev. Mol. Cell Biol. 12, 787-798 (2011).

80. Huang, H. et al. Using Fluorescence Quenching Titration to Determine the Orientation of a Model Transmembrane Protein in Mimic Membranes. Mater. 12, (2019).

81. Eytan, G. D. Use of liposomes for reconstitution of biological functions. Biochim Biophys Acta 694, 185-202 (1982).

82. Dröse, S., Galkin, A. \& Brandt, U. Proton pumping by complex I (NADH:ubiquinone oxidoreductase) from Yarrowia lipolytica reconstituted into proteoliposomes. Biochim. Biophys. Acta - Bioenerg. 1710, 87-95 (2005).

83. Gerber, G. E., Gray, C. P., Wildenauer, D. \& Khorana, H. G. Orientation of bacteriorhodopsin in Halobacterium halobium as studied by selective proteolysis. Proc. Natl. Acad. Sci. U. S. A. 74, 5426-5430 (1977).

84. Kalmbach, R. et al. Functional Cell-free Synthesis of a Seven Helix Membrane Protein: In situ Insertion of Bacteriorhodopsin into Liposomes. J. Mol. Biol. 371, 639-648 (2007).

85. Tunuguntla, R. et al. Lipid Bilayer Composition Can Influence the Orientation of Proteorhodopsin in Artificial Membranes. Biophys. J. 105, 1388-1396 (2013).

86. Wiedenmann, A., Dimroth, P. \& von Ballmoos, C. $\Delta \psi$ and $\Delta \mathrm{pH}$ are equivalent driving forces for proton transport through isolated F0 complexes of ATP synthases. Biochim. Biophys. Acta Bioenerg. 1777, 1301-1310 (2008).

87. Knol, J. et al. Unidirectional reconstitution into detergent-destabilized liposomes of the purified lactose transport system of Streptococcus thermophilus. J Biol Chem 271, 15358-15366 (1996).

88. Fang, G. et al. Manipulation of activity and orientation of membrane-reconstituted di-tripeptide transport protein DtpT of Lactococcus lactis. Mol. Membr. Biol. 16, 297-304 (1999).

89. Geest, M. van \& Lolkema Juke S. Membrane Topology and Insertion of Membrane Proteins: Search for Topogenic Signals. Microbiol. Mol. Biol. Rev. 64, 13-33 (2000).

90. Richard, P., Rigaud, J. L. \& Graber, P. Reconstitution of CFOF1 into liposomes using a new reconstitution procedure. Eur J Biochem 193, 921-925 (1990).

91. Levy, D., Gulik, A., Bluzat, A. \& Rigaud, J. L. Reconstitution of the sarcoplasmic reticulum Ca(2+)- 
ATPase: mechanisms of membrane protein insertion into liposomes during reconstitution procedures involving the use of detergents. Biochim Biophys Acta 1107, 283-298 (1992).

92. Pagano, A. \& Spiess, M. Reconstitution of Rab4-dependent vesicle formation in vitro. Methods Enzymol. 403, 81-92 (2005).

93. Öjemyr, L. N., Von Ballmoos, C., Faxén, K., Svahn, E. \& Brzezinski, P. The membrane modulates internal proton transfer in cytochrome c oxidase. Biochemistry 51, 1092-1100 (2012).

94. Happe, M., Teather, R. M., Overath, P., Knobling, A. \& Oesterhelt, D. Direction of proton translocation in proteoliposomes formed from purple membrane and acidic lipids depends on the $\mathrm{pH}$ during reconstitution. Biochim. Biophys. Acta - Biomembr. 465, 415-420 (1977).

95. Ritzmann, N. et al. Fusion Domains Guide the Oriented Insertion of Light-Driven Proton Pumps into Liposomes. Biophys. J. 113, 1181-1186 (2017).

96. Zheng, H., Lee, S., Llaguno, M. C. \& Jiang, Q.-X. bSUM: A bead-supported unilamellar membrane system facilitating unidirectional insertion of membrane proteins into giant vesicles. J. Gen. Physiol. 147, 77-93 (2016).

97. Schadauer, F. et al. Silica nanoparticles for the oriented encapsulation of membrane proteins into artificial bilayer lipid membranes. Langmuir 31, 2511-2516 (2015).

98. Geiss, A. F. et al. Proteo-lipobeads to encapsulate cytochrome c oxidase from Paracoccus denitrificans. J Colloid Interface Sci 500, 119-125 (2017).

99. Bronder, A. M. et al. Oriented Membrane Protein Reconstitution into Tethered Lipid Membranes for AFM Force Spectroscopy. Biophys J 111, 1925-1934 (2016).

100. Sumino, A., Uchihashi, T. \& Oiki, S. Oriented Reconstitution of the Full-Length KcsA Potassium Channel in a Lipid Bilayer for AFM Imaging. J. Phys. Chem. Lett. 785-793 (2017). doi:10.1021/acs.jpclett.6b03058

101. Jang, S. \& Javadov, S. Current Challenges in Elucidating Respiratory Supercomplexes in Mitochondria: Methodological Obstacles. Front. Physiol. 9, 238 (2018).

102. Liu, F., Lössl, P., Rabbitts, B. M., Balaban, R. S. \& Heck, A. J. R. The interactome of intact mitochondria by cross-linking mass spectrometry provides evidence for coexisting respiratory supercomplexes. Mol. Cell. Proteomics 17, 216-232 (2018).

103. Enríquez, J. A. Supramolecular Organization of Respiratory Complexes. Annu. Rev. Physiol. 78, 533-561 (2016).

104. Brzezinski, P. New Structures Reveal Interaction Dynamics in Respiratory Supercomplexes. Trends Biochem. Sci. 45, 3-5 (2020).

105. Biner, O., Fedor, J. G., Yin, Z. \& Hirst, J. Bottom-Up Construction of a Minimal System for Cellular Respiration and Energy Regeneration. ACS Synth. Biol. (2020). doi:10.1021/acssynbio.0c00110

106. Lee, C. et al. A two-domain elevator mechanism for sodium/proton antiport. Nature 501, 573577 (2013).

107. Uzdavinys, P. et al. Dissecting the proton transport pathway in electrogenic $\mathrm{Na}+/ \mathrm{H}+$ antiporters. Proc. Natl. Acad. Sci. U. S. A. 114, E1101-E1110 (2017).

108. Juge, N., Yoshida, Y., Yatsushiro, S., Omote, H. \& Moriyama, Y. Vesicular glutamate transporter contains two independent transport machineries. J. Biol. Chem. 281, 39499-39506 (2006).

109. Pols, T. et al. A synthetic metabolic network for physicochemical homeostasis. Nat. Commun. 
10, (2019).

110. Serdiuk, T. et al. YidC assists the stepwise and stochastic folding of membrane proteins. Nat. Chem. Biol. 12, 911-917 (2016).

111. Krenn, B. E., Koppenaal, F., Van Walraven, H. S., Krab, K. \& Kraayenhof, R. Co-reconstitution of the H+-ATP synthase and cytochrome b-563c-554 complex from a thermophilic cyanobacterium. Biochim. Biophys. Acta - Bioenerg. 1140, 271-281 (1993).

112. Von Ballmoos, C., Biner, O., Nilsson, T. \& Brzezinski, P. Mimicking respiratory phosphorylation using purified enzymes. Biochim. Biophys. Acta-Bioenerg. 1857, 321-331 (2016).

113. Nordlund, G., Brzezinski, P. \& Von Ballmoos, C. SNARE-fusion mediated insertion of membrane proteins into native and artificial membranes. Nat. Commun. 5, 1-8 (2014).

114. Biner, O., Schick, T., Muller, Y. \& von Ballmoos, C. Delivery of membrane proteins into small and giant unilamellar vesicles by charge-mediated fusion. FEBS Lett 590, 2051-2062 (2016).

115. Ishmukhametov, R. R., Russell, A. N. \& Berry, R. M. A modular platform for one-step assembly of multi-component membrane systems by fusion of charged proteoliposomes. Nat Commun 7 , 13025 (2016).

116. Rabe, M., Schwieger, C., Zope, H. R., Versluis, F. \& Kros, A. Membrane interactions of fusogenic coiled-coil peptides: Implications for lipopeptide mediated vesicle fusion. Langmuir 30, 77247735 (2014).

117. Stengel, G., Zahn, R. \& Höök, F. DNA-Induced Programmable Fusion of Phospholipid Vesicles. J. Am. Chem. Soc. 129, 9584-9585 (2007).

118. Chan, Y. H., van Lengerich, B. \& Boxer, S. G. Lipid-anchored DNA mediates vesicle fusion as observed by lipid and content mixing. Biointerphases 3, FA17 (2008).

119. Marsden, H. R., Tomatsu, I. \& Kros, A. Model systems for membrane fusion. Chem. Soc. Rev. 40, 1572-1585 (2011).

120. Raschle, T., Lin, C., Jungmann, R., Shih, W. M. \& Wagner, G. Controlled Co-reconstitution of Multiple Membrane Proteins in Lipid Bilayer Nanodiscs Using DNA as a Scaffold (Supporting Information). ACS Chem Biol 10, 2448-2454 (2015).

121. Serdiuk, T. et al. Insertion and folding pathways of single membrane proteins guided by translocases and insertases. Sci. Adv. 5, 1-11 (2019).

122. Tsien, R. Y. New Calcium Indicators and Buffers with High Selectivity Against Magnesium and Protons: Design, Synthesis, and Properties of Prototype Structures. Biochemistry 19, 2396-2404 (1980).

123. Minta, A. \& Tsien, R. Y. Fluorescent indicators for cytosolic sodium. J. Biol. Chem. 264, 1944919457 (1989).

124. Verkman, A. S. Development and biological applications of chloride-sensitive fluorescent indicators. Am. J. Physiol. - Cell Physiol. 259, (1990).

125. Berendes, R., Burger, A., Voges, D., Demange, P. \& Huber, R. Calcium influx through annexin V ion channels into large unilamellar vesicles measured with fura-2. FEBS Lett. 317, 131-134 (1993).

126. Rydström, J. Energy-linked nicotinamide nucleotide transhydrogenase. Properties of protontranslocating and ATP-driven transhydrogenase reconstituted from synthetic phospholipids and purified transhydrogenase from beef heart mitochondria. J. Biol. Chem. 254, 8611-9 (1979). 
127. Dufour, J. P., Goffeau, A. \& Tsong, T. Y. Active proton uptake in lipid vesicles reconstituted with the purified yeast plasma membrane ATPase. Fluorescence quenching of 9-amino-6-chloro-2methoxyacridine. J. Biol. Chem. 257, 9365-9371 (1982).

128. Wielandt, A. G., Palmgren, M. G., Fuglsang, A. T., Günther-Pomorski, T. \& Justesen, B. H. Measuring $\mathrm{H}+$ pumping and membrane potential formation in sealed membrane vesicle systems. in Methods in Molecular Biology 1377, 171-180 (Humana Press, New York, NY, 2016).

129. Graf, S., Brzezinski, P. \& von Ballmoos, C. The proton pumping bo oxidase from Vitreoscilla. Sci. Rep. 9, 1-10 (2019).

130. Waggoner, A. S. Dye indicators of membrane potential. Annu. Rev. Biophys. Bioeng. 8, 47-68 (1979).

131. Loew, L. M. Design and Use of Organic Voltage Sensitive Dyes. Advances in experimental medicine and biology 859, 27-53 (2015).

132. Miller, E. W. Small molecule fluorescent voltage indicators for studying membrane potential. Curr. Opin. Chem. Biol. 33, 74-80 (2016).

133. Liu, P. \& Miller, E. W. Electrophysiology, Unplugged: Imaging Membrane Potential with Fluorescent Indicators. Acc. Chem. Res. 53, 11-19 (2020).

134. Vetter, I. et al. High-Throughput Fluorescence Assays for lon Channels and GPCRs. in Advances in Experimental Medicine and Biology 1131, 27-72 (Springer, Cham, 2020).

135. Thelen, M., Petrone, G., O'Shea, P. S. \& Azzi, A. The use of fluoresceindipalmitoylphosphatidylethanolamine for measuring $\mathrm{pH}$-changes in the internal compartment of phospholipid vesicles. BBA - Bioenerg. 766, 161-168 (1984).

136. Etter, E. F., Minta, A., Poenie, M. \& Fay, F. S. Near-membrane [Ca2+] transients resolved using the Ca2+ indicator FFP18. Proc. Natl. Acad. Sci. U. S. A. 93, 5368-5373 (1996).

137. Ke, G. et al. A cell-surface-anchored ratiometric fluorescent probe for extracellular $\mathrm{pH}$ sensing. ACS Appl. Mater. Interfaces 6, 15329-15334 (2014).

138. Xiong, M. et al. A membrane-anchored fluorescent probe for detecting $\mathrm{K}+$ in the cell microenvironment. Chem. Commun. 52, 4679-4682 (2016).

139. Yao, H. W., Zhu, X. Y., Guo, X. F. \& Wang, H. An Amphiphilic Fluorescent Probe Designed for Extracellular Visualization of Nitric Oxide Released from Living Cells. Anal. Chem. 88, 9014-9021 (2016).

140. Ohgaki, R. et al. Ratiometric fluorescence imaging of cell surface $\mathrm{pH}$ by poly(ethylene glycol)phospholipid conjugated with fluorescein isothiocyanate. Sci. Rep. 7, 1-9 (2017).

141. Świtalska, A., Dembska, A., Fedoruk-Wyszomirska, A. \& Juskowiak, B. Cholesterol-bearing fluorescent g-quadruplex potassium probes for anchoring at the langmuir monolayer and cell membrane. Sensors (Switzerland) 18, (2018).

142. Cebecauer, M. \& Šachl, R. Lipophilic Fluorescent Probes: Guides to the Complexity of Lipid Membranes. in Fluorescent Analogs of Biomolecular Building Blocks 367-392 (John Wiley \& Sons, Inc, 2016). doi:10.1002/9781119179320.ch16

143. Kemmer, G. C. et al. Lipid-conjugated fluorescent $\mathrm{pH}$ sensors for monitoring $\mathrm{pH}$ changes in reconstituted membrane systems. Analyst 140, 6313-6320 (2015).

144. Schwamborn, M., Schumacher, J., Sibold, J., Teiwes, N. K. \& Steinem, C. Monitoring ATPase induced $\mathrm{pH}$ changes in single proteoliposomes with the lipid-coupled fluorophore Oregon 
Green 488. Analyst 142, 2670-2677 (2017).

145. Nichols, J. W. \& Deamer, D. W. Catecholamine uptake and concentration by liposomes maintaining pH gradients. BBA - Biomembr. 455, 269-271 (1976).

146. Bally, M. B., Hope, M. J., Van Echteld, C. J. A. \& Cullis, P. R. Uptake of safranine and other lipophilic cations into model membrane systems in response to a membrane potential. $B B A$ Biomembr. 812, 66-76 (1985).

147. Schubert, R., Wolburg, H., Schmidt, K. H. \& Roth, H. J. Loading of preformed liposomes with high trapping efficiency by detergent-induced formation of transient membrane holes. Chem. Phys. Lipids 58, 121-129 (1991).

148. Leiding, T. et al. Precise detection of $\mathrm{pH}$ inside large unilamellar vesicles using membraneimpermeable dendritic porphyrin-based nanoprobes. Anal. Biochem. 388, 296-305 (2009).

149. Xu, X., Khan, M. A. \& Burgess, D. J. Predicting hydrophilic drug encapsulation inside unilamellar liposomes. Int. J. Pharm. 423, 410-418 (2012).

150. Eloy, J. O. et al. Liposomes as carriers of hydrophilic small molecule drugs: Strategies to enhance encapsulation and delivery. Colloids Surfaces B Biointerfaces 123, 345-363 (2014).

151. Chiantia, S., Klymchenko, A. S. \& London, E. A novel leaflet-selective fluorescence labeling technique reveals differences between inner and outer leaflets at high bilayer curvature. Biochim Biophys Acta 1818, 1284-1290 (2012).

152. Dolder, N. \& von Ballmoos, C. Bifunctional DNA duplexes permit efficient incorporation of pH probes into liposomes. ChemBioChem cbic.202000146 (2020). doi:10.1002/cbic.202000146

153. Ying, L. et al. A cell-surface-anchored ratiometric i-motif sensor for extracellular pH detection. Chem. Commun. 52, 7818-7821 (2016).

154. Dembska, A., Bielecka, P. \& Juskowiak, B. pH-Sensing fluorescence oligonucleotide probes based on an i-motif scaffold: a review. Anal. Methods 9, 6092-6106 (2017).

155. Swiatkowska, A. \& Juskowiak, B. Effect of Cholesterol Anchoring Group on the Properties of GQuadruplex-Based FRET Probes for Potassium Ion. Chemosensors 2, 267-286 (2014).

156. Feng, G. et al. Engineering of Nucleic Acids and Synthetic Cofactors as Holo Sensors for Probing Signaling Molecules in the Cellular Membrane Microenvironment. Angew. Chemie - Int. Ed. 58, 6590-6594 (2019).

157. Qiu, L. et al. Cell membrane-anchored biosensors for real-time monitoring of the cellular microenvironment. J. Am. Chem. Soc. 136, 13090-13093 (2014).

158. Liu, L. et al. Cell Surface-Anchored DNA Nanomachine for Dynamically Tunable Sensing and Imaging of Extracellular pH. Anal. Chem. 90, 11198-11202 (2018).

159. Zeng, S. et al. Cell-Surface-Anchored Ratiometric DNA Tweezer for Real-Time Monitoring of Extracellular and Apoplastic pH. Anal. Chem. 90, 13459-13466 (2018).

160. Yuan, J. et al. Cell-Surface-Anchored Ratiometric DNA Nanoswitch for Extracellular ATP Imaging. ACS Sensors 4, 1648-1653 (2019).

161. Zhao, Y. et al. Single-molecule dynamics of gating in a neurotransmitter transporter homologue. Nature 465, 188-193 (2010).

162. Li, M. et al. Single Enzyme Experiments Reveal a Long-Lifetime Proton Leak State in a HemeCopper Oxidase. J Am Chem Soc 137, 16055-16063 (2015). 
163. Nishizaka, T., Hasimoto, Y. \& Masaike, T. Single Molecule Enzymology. Single Molecule Enzymology 778, (Humana Press, 2011).

164. English, B. P. et al. Ever-fluctuating single enzyme molecules: Michaelis-Menten equation revisited. Nat. Chem. Biol. 2, 87-94 (2006).

165. Volkán-Kacso, S. \& Marcus, R. A. What can be learned about the enzyme ATPase from singlemolecule studies of its subunit F1? Q. Rev. Biophys. 50, e14 (2017).

166. Veshaguri, S. et al. Direct observation of proton pumping by a eukaryotic P-type ATPase. Science (80-. ). 351, 1469-1473 (2016).

167. Berg, J., Block, S., Höök, F. \& Brzezinski, P. Single Proteoliposomes with E. coli Quinol Oxidase: Proton Pumping without Transmembrane Leaks. Isr. J. Chem. 57, 437-445 (2017).

168. Jorgensen, I. L., Kemmer, G. C. \& Pomorski, T. G. Membrane protein reconstitution into giant unilamellar vesicles: a review on current techniques. Eur Biophys J 46, 103-119 (2017).

169. Pautot, S., Frisken, B. J. \& Weitz, D. A. Production of unilamellar vesicles using an inverted emulsion. Langmuir 19, 2870-2879 (2003).

170. Funakoshi, K., Suzuki, H. \& Takeuchi, S. Formation of Giant Lipid Vesiclelike Compartments from a Planar Lipid Membrane by a Pulsed Jet Flow. J. Am. Chem. Soc. 129, 12608-12609 (2007).

171. Walde, P., Cosentino, K., Engel, H. \& Stano, P. Giant vesicles: preparations and applications. Chembiochem 11, 848-865 (2010).

172. Matosevic, S. \& Paegel, B. M. Layer-by-layer cell membrane assembly. Nat. Chem. 5, 958-963 (2013).

173. Deshpande, S., Caspi, Y., Meijering, A. E. C. \& Dekker, C. Octanol-assisted liposome assembly on chip. Nat. Commun. 7, 10447 (2016).

174. Stein, H., Spindler, S., Bonakdar, N., Wang, C. \& Sandoghdar, V. Production of Isolated Giant Unilamellar Vesicles under High Salt Concentrations. Front. Physiol. 8, 63 (2017).

175. Bellon, J. A., Pino, M. J. \& Wilke, N. Low-cost equipment for electroformation of Giant Unilamellar Vesicles. HardwareX 4, e00037 (2018).

176. Rideau, E., Wurm, F. R. \& Landfester, K. Self-Assembly of Giant Unilamellar Vesicles by Film Hydration Methodologies. Advanced Biosystems 1800324 (2019). doi:10.1002/adbi.201800324

177. Girish, V., Pazzi, J., Li, A. \& Subramaniam, A. B. Fabrics of Diverse Chemistries Promote the Formation of Giant Vesicles from Phospholipids and Amphiphilic Block Copolymers. Langmuir 35, 9264-9273 (2019).

178. Matsushita-Ishiodori, Y., Hanczyc, M. M., Wang, A., Szostak, J. W. \& Yomo, T. Using imaging flow cytometry to quantify and optimize giant vesicle production by water-in-oil emulsion transfer methods. Langmuir 35, 2375-2382 (2019).

179. Göpfrich, K. et al. One-Pot Assembly of Complex Giant Unilamellar Vesicle-Based Synthetic Cells. ACS Synth. Biol. 8, 937-947 (2019).

180. Noireaux, V. \& Libchaber, A. A vesicle bioreactor as a step toward an artificial cell assembly. Proc. Natl. Acad. Sci. 101, 17669-17674 (2004).

181. Gessesse, B., Nagaike, T., Nagata, K., Shimizu, Y. \& Ueda, T. G-protein coupled receptor protein synthesis on a lipid bilayer using a reconstituted cell-free protein synthesis system. Life $\mathbf{8}$, (2018). 
182. Ohta, N., Kato, Y., Watanabe, H., Mori, H. \& Matsuura, T. In vitro membrane protein synthesis inside Sec translocon-reconstituted cell-sized liposomes. Sci. Rep. 6, 1-9 (2016).

183. Biner, O., Schick, T., Ganguin, A. A. \& von Ballmoos, C. Towards a Synthetic Mitochondrion. Chim. Int. J. Chem. 72, 291-296 (2018).

184. Dezi, M., Di Cicco, A., Bassereau, P. \& Levy, D. Detergent-mediated incorporation of transmembrane proteins in giant unilamellar vesicles with controlled physiological contents. Proc Natl Acad Sci U S A 110, 7276-7281 (2013).

185. Hansen, J. S., Elbing, K., Thompson, J. R., Malmstadt, N. \& Lindkvist-Petersson, K. Glucose transport machinery reconstituted in cell models. Chem Commun 51, 2316-2319 (2015).

186. Spoelstra, W. K., Deshpande, S. \& Dekker, C. Tailoring the appearance: what will synthetic cells look like? Current Opinion in Biotechnology 51, 47-56 (2018).

187. Stano, P., Stano \& Pasquale. Is Research on "Synthetic Cells" Moving to the Next Level? Life 9, 3 (2018).

188. Berhanu, S., Ueda, T. \& Kuruma, Y. Artificial photosynthetic cell producing energy for protein synthesis. Nat. Commun. 10, 1325 (2019).

189. Lee, K. Y. K. A. et al. Photosynthetic artificial organelles sustain and control ATP-dependent reactions in a protocellular system. Nat. Biotechnol. 36, 530-535 (2018).

190. Hindley, J. W. et al. Building a synthetic mechanosensitive signaling pathway in compartmentalized artificial cells. Proc. Natl. Acad. Sci. U. S. A. 116, 16711-16716 (2019).

191. Chen, Z. et al. Synthetic beta cells for fusion-mediated dynamic insulin secretion. Nat. Chem. Biol. 14, 86-93 (2018).

192. Fischer, A., Oberholzer, T. \& Luisi, P. L. Giant vesicles as models to study the interactions between membranes and proteins. Biochim. Biophys. Acta-Biomembr. 1467, 177-188 (2000).

193. Nishimura, K. K. et al. Identification of giant unilamellar vesicles with permeability to small charged molecules. RSC Adv. 4, 35224-35232 (2014).

194. Beales, P. A., Khan, S., Muench, S. P. \& Jeuken, L. J. C. Durable vesicles for reconstitution of membrane proteins in biotechnology. Biochem. Soc. Trans. 45, 15-26 (2017).

195. Rideau, E., Dimova, R., Schwille, P., Wurm, F. R. \& Landfester, K. Liposomes and polymersomes: a comparative review towards cell mimicking. Chem. Soc. Rev. 47, 8572-8610 (2018).

196. Schmitt, C., Lippert, A. H., Bonakdar, N., Sandoghdar, V. \& Voll, L. M. Compartmentalization and transport in synthetic vesicles. Front. Bioeng. Biotechnol. 4, 1-12 (2016).

197. Klermund, L., Poschenrieder, S. T. \& Castiglione, K. Biocatalysis in Polymersomes: Improving Multienzyme Cascades with Incompatible Reaction Steps by Compartmentalization. ACS Catal. 7, 3900-3904 (2017).

198. Schwarzer, T. S., Klermund, L., Wang, G. \& Castiglione, K. Membrane functionalization of polymersomes: Alleviating mass transport limitations by integrating multiple selective membrane transporters for the diffusion of chemically diverse molecules. Nanotechnology 29, (2018).

199. Khan, S., Li, M., Muench, S. P., Jeuken, L. J. C. C. \& Beales, P. A. Durable proteo-hybrid vesicles for the extended functional lifetime of membrane proteins in bionanotechnology. Chem. Commun. 52, 11020-11023 (2016). 
200. Otrin, L. et al. Toward Artificial Mitochondrion: Mimicking Oxidative Phosphorylation in Polymer and Hybrid Membranes. Nano Lett. 17, 6816-6821 (2017).

201. Marušič, N. et al. Constructing artificial respiratory chain in polymer compartments: Insights into the interplay between bo3 oxidase and the membrane. Proc. Natl. Acad. Sci. U. S. A. 117, (2020).

202. Al Nahas, K. et al. A microfluidic platform for the characterisation of membrane active antimicrobials. Lab Chip 19, 837-844 (2019).

203. Schaich, M. et al. An Integrated Microfluidic Platform for Quantifying Drug Permeation across Biomimetic Vesicle Membranes. Mol. Pharm. 16, 2494-2501 (2019).

204. Futai, M. Orientation of membrane vesicles from Escherichia coli prepared by different procedures. J. Membr. Biol. 15, 15-28 (1974).

205. Miyazaki, R. et al. A Novel SRP Recognition Sequence in the Homeostatic Control Region of Heat Shock Transcription Factor o32. Sci. Rep. 6, 1-11 (2016).

206. Seigneuret, M. \& Rigaud, J. L. Partial separation of inwardly pumping and outwardly pumping bacteriorhodopsin reconstituted liposomes by gel filtration. FEBS Lett. 228, 79-84 (1988).

207. Young, H. S., Rigaud, J. L., Lacapère, J. J., Reddy, L. G. \& Stokes, D. L. How to make tubular crystals by reconstitution of detergent-solubilized Ca2(+)-ATPase. Biophys J 72, 2545-2558 (1997).

208. Verkhovskaya, M. L. et al. Glutamic acid 286 in subunit I of cytochrome $b_{3}$ is involved in proton translocation. Proc. Natl. Acad. Sci. U. S. A. 94, 10128-31 (1997).

209. Knol, J., Sjollema, K. \& Poolman, B. Detergent-mediated reconstitution of membrane proteins. Biochemistry 37, 16410-16415 (1998).

210. Wang, L. \& Sigworth, F. J. Structure of the BK potassium channel in a lipid membrane from electron cryomicroscopy. Nature 461, 292-295 (2009).

211. Nomura, T., Cox, C. D., Bavi, N., Sokabe, M. \& Martinac, B. Unidirectional incorporation of a bacterial mechanosensitive channel into liposomal membranes. FASEB J. 29, 4334-4345 (2015).

212. Dixon, J. F. \& Hokin, L. E. The reconstituted (Na,K)-ATPase is electrogenic. J. Biol. Chem. 255, 10681-10686 (1980).

213. Hokin, L. E. \& Dixon, J. F. Reconstitution of the Na,K-Pump by Freeze-thaw Sonication: Estimation of Coupling Ratio and Electrogenicity. Methods Enzymol. 156, 141-155 (1988).

214. Pfleger, N. et al. Solid-state NMR and functional studies on proteorhodopsin. Biochim. Biophys. Acta - Bioenerg. 1787, 697-705 (2009).

215. Rigaud, J. L., Paternostre, M. T. \& Bluzat, A. Mechanisms of membrane protein insertion into liposomes during reconstitution procedures involving the use of detergents. 2. Incorporation of the light-driven proton pump bacteriorhodopsin. Biochemistry 27, 2677-2688 (1988). 